\title{
Impact of large-scale circulation changes in the North Atlantic sector on the current and future Mediterranean winter hydroclimate
}

\author{
Monika J. Barcikowska ${ }^{1} \cdot$ Sarah B. Kapnick $^{2} \cdot$ Frauke Feser $^{3}$
}

Received: 31 July 2016 / Accepted: 15 May 2017 / Published online: 7 June 2017

(c) The Author(s) 2017. This article is an open access publication

\begin{abstract}
The Mediterranean region, located in the transition zone between the dry subtropical and wet European mid-latitude climate, is very sensitive to changes in the global mean climate state. Projecting future changes of the Mediterranean hydroclimate under global warming therefore requires dynamic climate models to reproduce the main mechanisms controlling regional hydroclimate with sufficiently high resolution to realistically simulate climate extremes. To assess future winter precipitation changes in the Mediterranean region we use the Geophysical Fluid Dynamics Laboratory high-resolution general circulation model for control simulations with pre-industrial greenhouse gas and aerosol concentrations which are compared to future scenario simulations. Here we show that the coupled model is able to reliably simulate the large-scale winter circulation, including the North Atlantic Oscillation and Eastern Atlantic patterns of variability, and its associated impacts on the mean Mediterranean hydroclimate. The model also realistically reproduces the regional features of daily heavy rainfall, which are absent in lowerresolution simulations. A five-member future projection ensemble, which assumes comparatively high greenhouse
\end{abstract}

Electronic supplementary material The online version of this article (doi:10.1007/s00382-017-3735-5) contains supplementary material, which is available to authorized users.

Monika J. Barcikowska

mbarcikowska@edf.org

1 Princeton University, GFDL Princeton University Forrestal Campus, Princeton, NJ, USA

2 Geophysical Fluid Dynamics Laboratory, National Ocean and Atmospheric Administration, Princeton, USA

3 Helmholtz-Zentrum Geesthacht Centre for Materials and Coastal Research, Geesthacht, Germany gas emissions (RCP8.5) until 2100, indicates a strong winter decline in Mediterranean precipitation for the coming decades. Consistent with dynamical and thermodynamical consequences of a warming atmosphere, derived changes feature a distinct bipolar behavior, i.e. wetting in the north-and drying in the south. Changes are most pronounced over the northwest African coast, where the projected winter precipitation decline reaches $40 \%$ of present values. Despite a decrease in mean precipitation, heavy rainfall indices show drastic increases across most of the Mediterranean, except the North African coast, which is under the strong influence of the cold Canary Current.

\section{Introduction}

The Mediterranean region is located in the transition zone between the arid to semiarid Subtropical Desert Climate and the more humid central to Northern European climate. It is characterized by mild, wet winters and hot, dry summers (Koeppen 1936). The southern part of the region is mostly under the influence of the descending branch of the Hadley Cell and the cold surface water of the Canary Current, which promote very stable and dry conditions in this region. The northern part, by contrast, is controlled by mid-latitude storm tracks variability and the North Atlantic Oscillation (hereafter, NAO, Hurrell 1995; Dai et al. 1997; Rodo et al. 1997). Its location in a subtropical versus extra-tropical transition zone coupled with complex morphology, high mountain ridges, peninsulas and islands, makes the Mediterranean climate very sensitive to changes in atmospheric circulation. Based on global warming projections (Giorgi 2006), the region is one of the most responsive to the future climate change, thus often referred to as a "hot spot". The complex geo-political location and 
socio-economic structure of this region makes populations particularly exposed and vulnerable to climate change and its extremes.

Winter precipitation in the Mediterranean might be impacted by anthropogenic climate change through several dynamic and thermodynamic processes. Dynamically, the expanding Hadley Cell (Lu et al. 2007; Johanson and Fu 2009; Kang and Lu 2012), the corresponding anomalous subsidence and divergence on its poleward flank, and the northeastward shift of mid-latitude storm-tracks (Yin 2005; $\mathrm{Lu}$ et al. 2007; Wu et al. 2011; Feser et al. 2015), can all influence the winter Mediterranean hydroclimate. As a thermodynamic response of a warming atmosphere, the hydrological cycle is expected to intensify, so the wet areas become wetter and dry areas, such as subtropics, (e.g. the Mediterranean) become drier (Held and Soden 2006). Increasing maximum atmospheric water vapor content will likely impact the intensity of precipitation events, and thus is of primary importance for changes in extreme precipitation over the region (Emori and Brown 2005; Kunkel et al. 2013).

The Coupled Model Intercomparison Project 3 (CMIP3) generation of global climate models (GCMs, with horizontal resolution of $\sim 280 \mathrm{~km}$ ) was able to capture the largescale mean climatology of the Mediterranean hydroclimate and its response to various global warming scenarios. Giorgi and Lionello (2008) showed that projected mean annual rainfall might decrease up to $30 \%$ in the southern Mediterranean. These changes are consistent with CMIP5generation simulations as well as with observations, which in recent decades have shown significant drying in the subtropical regions of the Northern Hemisphere (Trenberth et al. 2007; Zhang et al. 2007; Trenberth 2011).

At the same time, an increase in recorded extreme precipitation was detected in many regions of the Northern Hemisphere (Alexander et al. 2006; Min et al. 2011; Westra et al. 2013). CMIP5 projections (Sillmann et al. 2013) confirmed that for some regions including the Mediterranean, heavy rainfall indices will increase despite the mean decline. Nevertheless, due to the coarse resolution of these GCMs, precipitation extremes (and their changes) associated with global warming are still underestimated by GCM models (Sillmann et al. 2013; Van der; Wiel et al. 2016).

Kelley et al. (2011) showed that the increased horizontal resolution in CMIP5 $(\sim 200 \mathrm{~km})$ models potentially allowed for a spatial refinement in the simulated geographical pattern and for improvements in the simulated amplitude of precipitation indices. However, for the climate transition zones like the Mediterranean region, which are influenced additionally by local factors, i.e. complex topography and land-sea contrast, high-resolution modeling or downscaling methodologies are necessary to obtain a realistic representation of climate extremes.
Results coming from Regional Climate Model (RCM) projections are quite heterogeneous. But a large fraction of these studies (Semmler and Jacob 2004; Goubanova and Li 2007; Gao et al. 2006; Paxian et al. 2015), consistently with the GCMs simulations, points to an increase in projected extreme rainfall indices in the northern part of the Mediterranean and decrease (Beniston et al. 2007) in the southern domain.

Kitoh and Endo (2016), on the other hand, used a 20-km resolution atmospheric general circulation model (AGCM, run with fixed sea surface temperature fields) to capture reasonably well the magnitude of precipitation extremes. They found an increase in maximum 5- and 1-day winter precipitation totals in the northern Mediterranean, despite a general drying in the winter season, in response to the RCP8.5 scenario. Nevertheless, the lack of coupled air-sea interactions in their experiment could impact the simulated precipitation in coastal regions like the western Mediterranean, which is under the strong influence of the cold Canary Current.

On the other hand, studies investigating the Mediterranean winter hydroclimate (Kelley et al. 2011; Barkhordarian et al. 2013) indicate a large contribution of internal variability to the recently observed decline. Kelley et al. (2011) attributed the late twentieth century winter drying (the 1960s-1990s) in the Mediterranean to the NAO, related mostly to multidecadal climate variability, with a much smaller fraction related to radiative forcing. The northern subdomain is strongly controlled by mid-latitude variability. Winter precipitation, particularly in the western region, shows a strong anti-correlation with the NAO (Hurrell 1995; Dai et al. 1997; Rodo et al. 1997; Xoplaki 2002; Trigo et al. 2004; Gomes 2001, 2011), which partly controls storm tracks transporting moisture. Mariotti and Dell'Aquila (2012) have shown that the NAO variability, which represents the main sea level pressure (SLP) pattern in the North Atlantic sector, explains (in winter) up to $30 \%$ of the decadal precipitation changes in the Mediterranean region. Other studies (Moore 2012; Seierstad et al. 2007; Moore and Renfrew 2012; Rodriguez-Puebla et al. 1998; Dunkeloh and Jacobeit 2003; Xoplaki et al. 2004; Hurrell et al. 2004) have highlighted the importance of other atmospheric components, including the Eastern Pacific pattern, which modulates the impact of the NAO on North Atlantic storm tracks, European and North African thermal and hydrological climate.

Overall, analyzing and projecting the Mediterranean climate has challenges remaining to be overcome. Without sufficiently long control simulations, studies of precipitation variability are confided to decadal timescales and are unable to quantify lower frequency variability. Historically, low spatial resolution has limited the ability of GCMs to simulate features of not only regional climate, but also 
large-scale circulation. Moreover, regional changes in extremes do not necessarily scale with global mean climate, and vice versa. Therefore, increasing spatial and temporal resolution in GCMs may potentially improve the representation of the simulated mean climate, climate/weather extremes and their changes. However, corresponding with this approach is increasing variance, as regional factors and weather-time scale variability start playing a role. This requires further computational efforts, involving long control run integrations or sufficiently large ensembles, to enable robust detection and attribution of climate change response. Employing RCMs on the other hand, requires tackling with the models' internal variability, e.g. by applying techniques like spectral nudging (e.g. von Storch et al. 2000). This technique corrects large-scale mean climate state by nudging it towards the observed one. Therefore, taking for the account nonstationarity of climate and no reference data for the future, an application of this method is more suitable for the simulations of the past and present climate.

To explore the internal and radiatively forced multidecadal Mediterranean wintertime climate variations and quantify the need for a high resolution fully coupled multicentury experiment, we use both a 1000 year control run with fixed atmospheric forcings from two different models and a five-member ensemble of integrations with varying atmospheric forcings. Analyses of control runs from the Geophysical Fluid Dynamics Laboratory (GFDL) Climate Model version 2.5 (CM2.5) general circulation model and its lower resolution predecessor, CM2.1, allow us to analyze the impact of the spatial resolution on the simulated large-scale circulation. The 1000 year control runs provides a rare opportunity to investigate contributions of multidecadal internal climate variations to the long-term changes in the Mediterranean hydroclimate. Addressing this issue has been given little attention till now, owing to the limited length of control runs and observations. Application of multi-channel singular spectrum analysis (Allen and Robertson 1996) enables us to isolate fingerprints of components, which explicitly dominate multidecadal time scales. Five-member ensembles of historical runs and future projections (see Sect. 2.2 for details) facilitate the extraction of robust fingerprints of future climate change. High spatial and temporal resolution data provides a unique opportunity to address the question: "What changes in the winter Mediterranean climate/weather should we expect by the end of the century in terms of both mean and extreme precipitation?"

The structure of the study is as follows: Sect. 2 describes data and methods. Section 3.1 compares resolution-dependent features of the North Atlantic atmospheric circulation. The control run is validated with observations in terms of the simulated atmospheric circulation, mean precipitation and precipitation extremes. In Sects. 3.2 and 3.3 we present spatio-temporal fingerprints of multidecadal largescale atmospheric internal variations and their impact on the Mediterranean winter precipitation. Section 4 focuses on the climate response to changing radiative forcing, as defined in the Intergovernmental Panel on Climate Change (IPCC) RCP8.5 scenario. Following this is an analysis of daily precipitation, with special attention put on precipitation extremes. Section 5 discusses and concludes the presented results.

\section{Data and methods}

\subsection{Model and observational data}

This study analyzes two long control simulations, where greenhouse gases and aerosols composition are held fixed at 1860 levels. The GFDL CM2.5 model (CM2.5) provides a 1000 year control run. CM2.5 has an atmospheric and land surface horizontal grid distance of approximately $50 \mathrm{~km}$ and vertical resolution of 32 levels. The horizontal grid distance of the ocean increases from $28 \mathrm{~km}$ in the tropics to $8 \mathrm{~km}$ in the high latitudes. For comparison to assess the role of resolution, we analyzed a 4000 year run from the CM2.5 model's predecessor, the GFDL CM2.1 model (CM2.1). This model incorporates a grid distance of $2^{\circ}$ latitude $\times 2.5^{\circ}$ longitude for the atmosphere. The resolution for the ocean is nonuniform, with approximately $1^{\circ}$ latitude $\times 1^{\circ}$ longitude; and finer meridional resolution in the tropics. CM2.1 model has 24 vertical levels. It has coarsely resolved stratosphere, compared to CM2.5, which may negatively impact a representation of the stratosphere-troposphere interactions, climate variability and change. Details of the CM2.1 and CM2.5 model simulation features can be found in Delworth et al. (2006, 2012).

Impacts of climate change are investigated using a fivemember ensemble of CM2.5 simulations with changing radiative forcing over the period 1861-2100. The forcing follows the protocols of the Coupled Model Intercomparison Project Phase 5 (http://cmip-pcmdi.llnl.gov/cmip5/ forcing.html). For 1861-2005, the radiative forcings are based on observational estimates of concentrations of wellmixed greenhouse gases (GHG), ozone, volcanos, aerosols, solar irradiance changes and land-use distribution. Radiative forcing for the period 2006-2100 follows an estimate of projected changes defined in the IPCC RCP8.5 scenario (Meinshausen et al. 2011; Riahi et al. 2011). This scenario assumes high population growth, slow technological change and energy intensity improvements, lack of developed climate change policies, which results in large energy demand and GHG emissions. 
The analysis of the simulated large-scale circulation uses monthly means of hydro-meteorological variables for the winter (December, January, February, hereafter DJF) season. The simulated features were compared with reanalysis-based monthly pressure at mean sea level (hereafter SLP) and monthly precipitation rates (hereafter PRECIP) for the period 1951-2010. The data sets are provided by NOAA-CIRES twentieth century reanalysis V2c (20CR, Compo et al. 2011, http://www.esrl.noaa.gov/psd/data/20thC_Rean/). For comparison of the large-scale features, all variables were interpolated to $5^{\circ}$ latitude $\times 5^{\circ}$ longitude grid.

For validation of the simulated hydro-meteorological variables, we used the NOAA-CIRES twentieth century reanalysis V2c (20CR) and GPCC precipitation data V6 (Schneider et al. 2011), provided by NOAA/OAR/ESRL PSD (http://www.esrl.noaa.gov/psd/). The first one provides $\sim 2^{\circ}$ resolution monthly surface precipitation rates. The GPCC Precipitation Full V6 provides $0.5^{\circ}$ resolution monthly totals of precipitation for the 1901-2010 period. For analysis of daily precipitation data, we use E-OBS v.12 (Haylock et al. 2008; http://www.ecad.eu), provided by European Climate Assessment and Dataset. The dataset contains daily precipitation sums on a $0.25^{\circ}$ regular latitude-longitude grid for the period 1950-2015.

\subsection{Methods}

Variability of the North Atlantic atmospheric circulation and its physical linkage to the Mediterranean winter hydroclimate was analyzed with linear regression and Multi-Channel Singular Spectrum Analysis (MSSA, Plaut and Vautard 1994; Allen and Smith 1996; Moron et al. 1998; Ghil et al. 2002). We are interested in the long-term changes, and variability on at least multidecadal time-scale. Hence MSSA, which is a time-selective method, serves better its purpose than the standard empirical orthogonal function analysis. This approach is also more likely to extract a single, dynamically meaningful mode of variability, assuming that physical mechanisms act on their preferential time scales.

Application of MSSA allowed us to isolate dominant spatio-temporal fingerprints of seasonal (here we use DJF) ocean-atmosphere variability on multidecadal scale. MSSA is an extended version of the Singular Spectrum Analysis, which calculates eigenvalues and eigenvectors of a covariance matrix. The matrix is created with M-lagged copies of vector time series, sampled at equal intervals. Here we apply MSSA to search for spatially coherent temporal patterns of DJF SLP, SST (sea surface temperature) and precipitation. In this application a time interval is one DJF season, and a time-lag window has $M=80$. Sensitivity of the results was tested with
$70<\mathrm{M}<100$, but were not found to alter our main findings (not shown). MSSA was applied to data sets, with dimensions reduced to the first 20 PCA components, explaining generally more than $80 \%$ of variance. Statistical significance of derived components has been tested against a red noise hypothesis, using Chi-Square test. Prior to conducting the analysis, data was interpolated to a $5^{\circ} \times 5^{\circ}$ horizontal grid, standardized to zero mean and unit variance, and smoothed with a 15 -year running mean filter.

Linear regression analysis was performed between seasonal (December-February) SLP, vorticity and precipitation. The significance of the derived relationship was tested with a F-statistic test for the analysis of variance. Prior to the analysis data sets were standardized to zero mean and unit variance.

The regional climate change analysis concentrates on the Mediterranean region, defined by $30-45^{\circ} \mathrm{N}$, $10^{\circ} \mathrm{W}-40^{\circ} \mathrm{E}$ (following MED region in AR5 IPCC report), which includes two subdomains: $28-38^{\circ} \mathrm{N}, 10^{\circ} \mathrm{W}-40^{\circ} \mathrm{E}$ and $38-47^{\circ} \mathrm{N}, 10^{\circ} \mathrm{W}-40^{\circ}$. As a reference period we use the 1961-1999 and 2061-2099 DJF seasons (hereafter referred to as the present and future periods, respectively). The length of 40 years was chosen to reduce the effect of long-time scale internal variability and to ensure that sufficient information is provided for statistical inference about extremes. For calculation of fractional changes, the derived changes were normalized by the values in the present period (1961-1999).

The extreme precipitation analysis is based on the percentiles of daily total precipitation ratio and three indices. Two indices are the ones suggested by the Expert Team on Climate Change Detection and Indices (Klein Tank et al. 2009). These are seasonal (DJF) maximum 5-day precipitation totals (R5d) and 1-day precipitation total (R1d). Additionally, the Generalized Extreme Value theory (GEV, Coles 2001; Smith 2003; Wilks 2006) was applied to block (seasonal) maxima in 40-year sample periods, to analyze changes in terms of return values. Return values (RV) for a given return period $(\mathrm{T})$ are defined as values expected to be exceeded once per T-years. RVs are estimated as quantiles $\left[(1-1 / \mathrm{T})^{\prime}\right.$ th quantile] of a sample fitted to the GEV model. For example the 90th quantile $(10 \%$ exceedance probability) is an RV for $\mathrm{T}=10$-year period. The analysis here focuses on 10-year period RVs, because estimations for longer periods (e.g. 50-year period with exceedance probability of $2 \%$ ) is more prone to sampling errors and biases due to limited information about the shape of a distribution, given relatively short samples. The GEV distribution comprises three types [Gumbel, Frechet, Weibull (Jenkinson 1955)] of asymptotic extreme value distributions. Their parameters (location, scale and shape) are estimated here with the maximum likelihood method. 
Validation of a GEV-based extrapolation is limited, although, the analysis here uses all available sources. The assessment of the goodness of fit of the GEV model involved a comparison of model-based and empirical estimates of the distribution function using the Kolmogorov-Smirnov goodness of fit test. Overall the test suggests that the derived GEV fitting can provide reasonable approximations of seasonal extreme precipitation. Most coastal regions in the northern Mediterranean passed the goodness of fit test, but the reliability in semiarid regions (particularly northwest Africa) is limited.

\section{Large-scale circulation and its impacts on the mean Mediterranean hydroclimate}

The observed winter Mediterranean climate is closely tied to the atmospheric circulation over the North Atlantic. Therefore in this section we validate the GFDL CM2.1 and CM2.5 models' ability to reproduce mechanisms governing the Mediterranean hydrological cycle. First we focus on the simulated large-scale mean atmospheric state and precipitation fields over the North Atlantic-European sector. In the further part we wish to obtain more comprehensive information on the long-term climatic changes. We investigate the models' skill in simulating multidecadal climate variations over the North Atlantic and their relative importance for the Mediterranean hydroclimate. Spatio-temporal patterns, dominating multidecadal variability of SST and atmosphere, are extracted with the Multi-Channel Singular Spectrum Analysis. The physical link between these patterns and Mediterranean winter mean precipitation is diagnosed in the last part of the section.

\subsection{Mean atmospheric state over the North Atlantic and European sector}

Circulation in the mid-latitudes is determined mostly by the intensity of the meridional SLP gradient over the North Atlantic (in other words the phase of the NAO, Hurrell et al. 2003), which governs the zonal mean flow and directions of storm tracks transporting moisture towards Europe. In case of a strong pressure gradient (NAO+), the storm track becomes more zonal and hence precipitation is directed more towards central Europe while a weak gradient (NAO-) redirects cyclones with increased precipitation towards southern Europe and the Mediterranean region. Strong, upper level westerlies between polar and subtropical air masses over the Euro-Atlantic region, which characterize the jet stream, are usually tilted towards the north-east. This tilt is mostly associated with the land-sea contrast. Models with low horizontal resolution often struggle to correctly reproduce these features (Nakamura and
Wallace 1993; Woolings et al. 2010; Jung et al. 2012). Therefore, mean flow and associated storm tracks simulated with CMIP5 models (Zappa et al. 2013a, b) are often too zonal and displaced southward. In CM2.5, which has higher resolution than CMIP5 and its predecessor CM2.1, this bias is considerably lower (Delworth et al. 2012; Yang and Christensen 2012).

The comparison of simulated large-scale dynamical fields with reanalysis data (Fig. 1, all fields smoothed to $5^{\circ} \times 5^{\circ}$ lat-lon grid) shows that both GFDL models reproduce realistic mean airflow features. The sharpest SLP gradient (where the NAO is located) is concentrated between the Icelandic Low/Azores High: the regions with maximum precipitation are collocated with the jet stream and storm tracks. Nevertheless, the mean airflow in the low-resolution CM2.1 shows a zonal bias (see contours of differences between CM2.1 and observations), explained by Delworth et al. (2012) with a too weak trough in the $500 \mathrm{hPa}$ geopotential height over northeast North America. In CM2.5, the mean airflow and precipitation patterns resemble the observed geographical patterns more closely. Apart from this, the finer orography yields a more realistic representation of precipitation over land. The patterns in CM2.5 are more distinct and gradients are sharper, particularly for coastal regions, e.g. the west coasts of the United Kingdom, Scandinavia and the Iberian Peninsula (as shown in Delworth et al. 2012).

Figures 1 and 2 (left) also show that the skill of CM2.5 in simulating precipitation over the Mediterranean is also improved, relative to the CM2.1. Although precipitation across the CM2.1, CM2.5, 20CR and GPCC data sets does not differ greatly, the positive bias over the northern Iberian Peninsula and negative bias over the Balkan Peninsula (contours in Fig. 1) are distinctively reduced in CM2.5. It is also worth noting that the 20CR precipitation data set itself may have errors that contribute to the derived regional biases. Krueger et al. (2013) suggested that the 20CR data set, which relies on surface pressure, sea surface temperature and ice extent, contains temporal inhomogeneities. The accuracy of the observations and their spatio-temporal coverage underwent a significant improvement over time. This most likely impacts the quality of the dataset and may limit its suitability for certain types of analysis like the derivation of long-term trends.

The simulated daily heavy rainfall (90th percentiles) also shows a very good agreement with observations (Fig. 2 (right), CM2.5 with $0.5^{\circ} \times 0.5^{\circ}$ and EOBS with $0.25^{\circ} \times 0.25^{\circ}$ horizontal resolution), capturing the structure and sharp gradients in the orographically complex subdomains. In some regions (e.g. the northwest coast of the Balkan Peninsula, the Alpine region and the west coast of Turkey) the simulated values are lower than the observed ones, indicating a room for improvement, potentially obtained by 


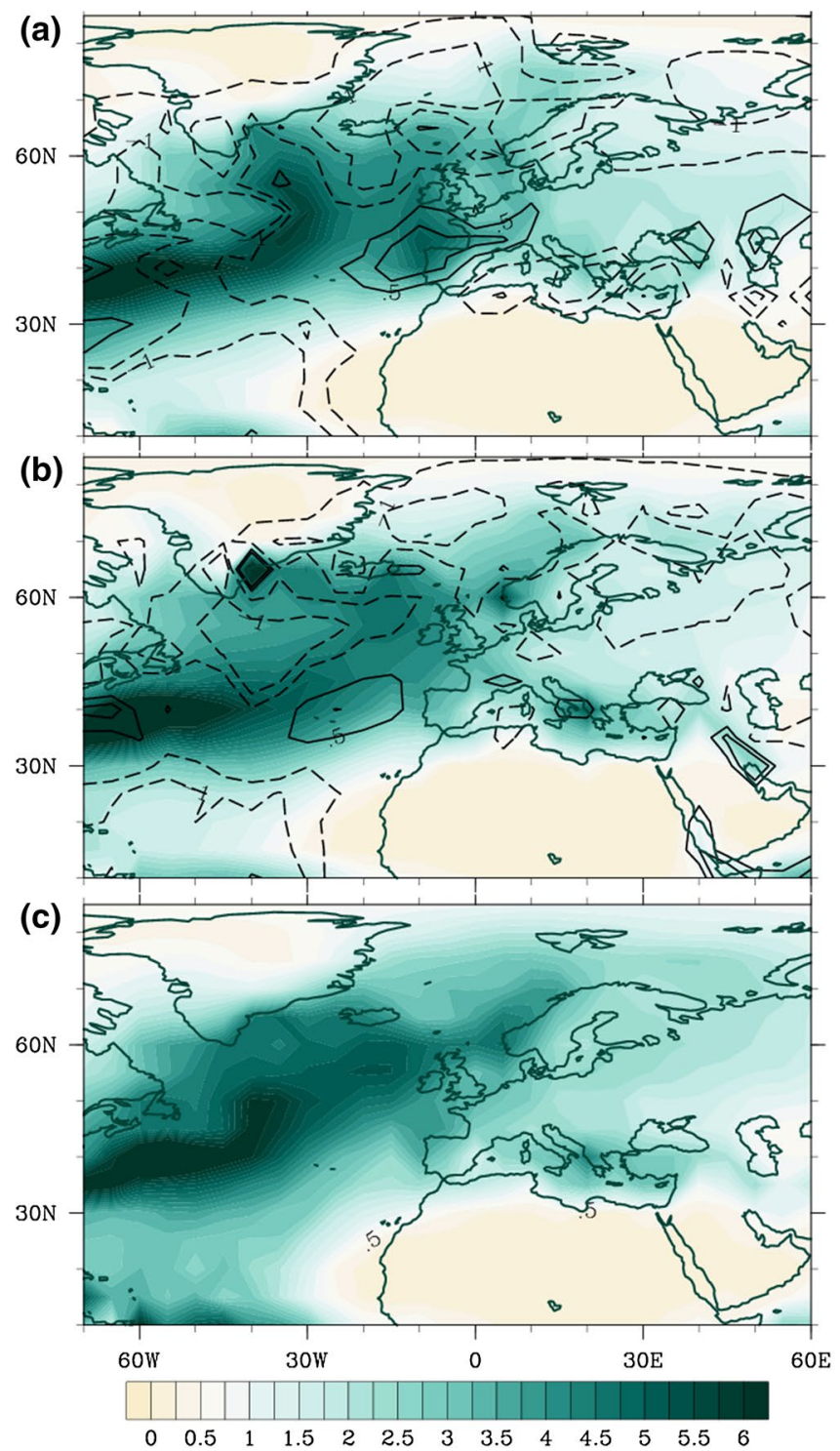

Fig. 1 Precipitation [left, (mm/day)] and SLP [right, (hPa)] averaged over the months of December-February for control run in the a GFDL CM2.1, b CM2.5 model and $\mathbf{c}$ reanalysis data (twentieth century reanalysis). Contours in $\mathbf{a}$ and $\mathbf{b}$ show differences in reference

increasing horizontal resolution. Another analysis of precipitation simulated with CM2.5 can be found in Delworth et al. (2012).

Overall, the higher resolution CM2.5 runs give better representation of both the large-scale circulation and regional-scale features of mean precipitation. These improvements correspond with a high skill in capturing regional daily precipitation extremes, most probably due to improved representation of the storm tracks. Given the limited availability/reliability of the observations in the Mediterranean before satellite era, the CM2.5 long control run

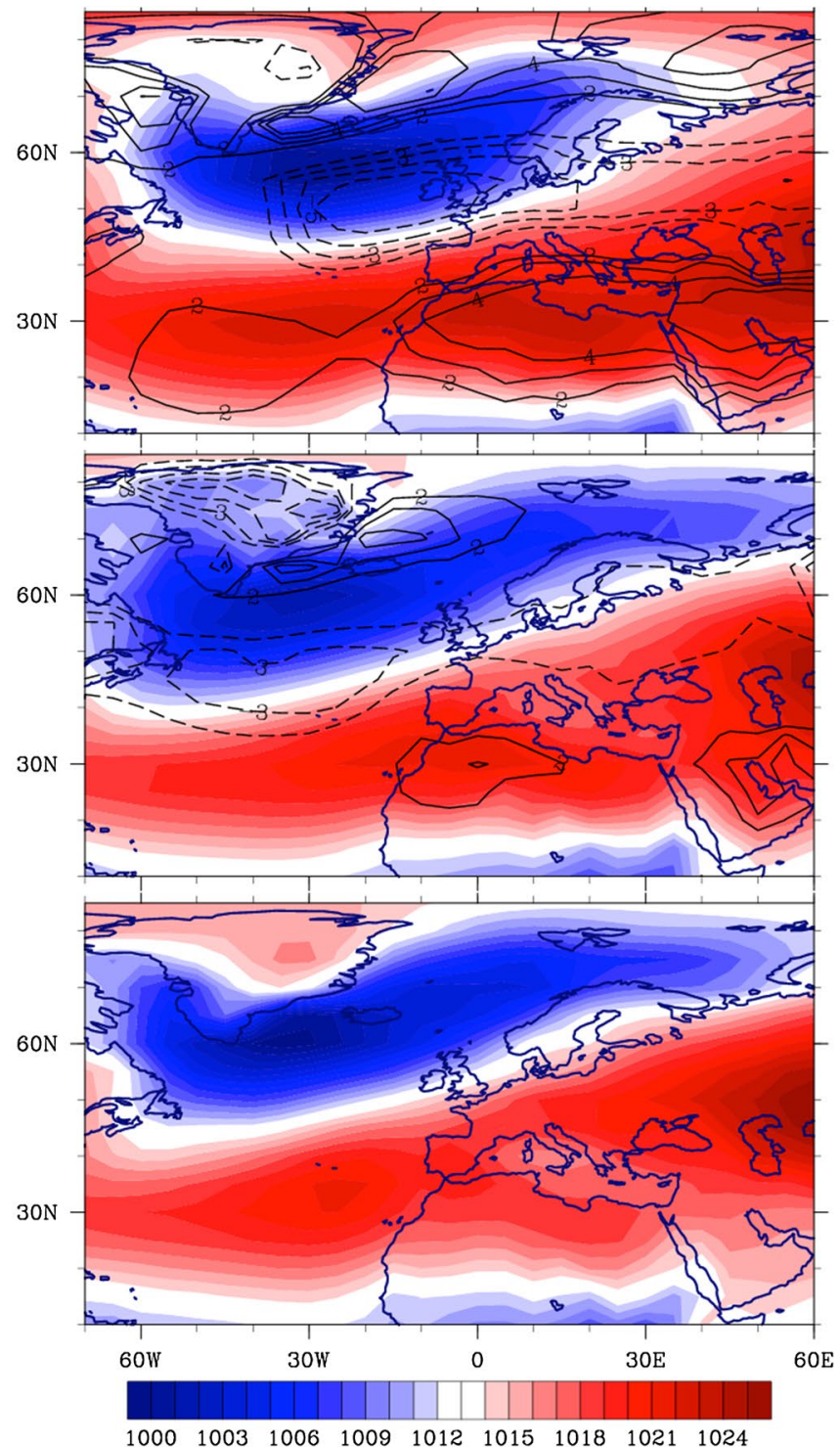

to the reanalysis, with negative values dashed. The variables shown were interpolated to a common $5^{\circ} \times 5^{\circ}$ grid and averaged over the period 100-999 for CM2.1 and CM2.5, 1910-2010 for observations

can provide more plausible information. Therefore in the remaining Sects. 3.2 and 3.3 we will mostly present results from CM2.5.

\subsection{Multidecadal scale climate variability in the North Atlantic sector}

The atmospheric large-scale circulation over the North Atlantic, dominated by the NAO and East Atlantic (EA, Barnston and Livezey 1987) patterns of variability, yields a pronounced impact not only on the European but also on 


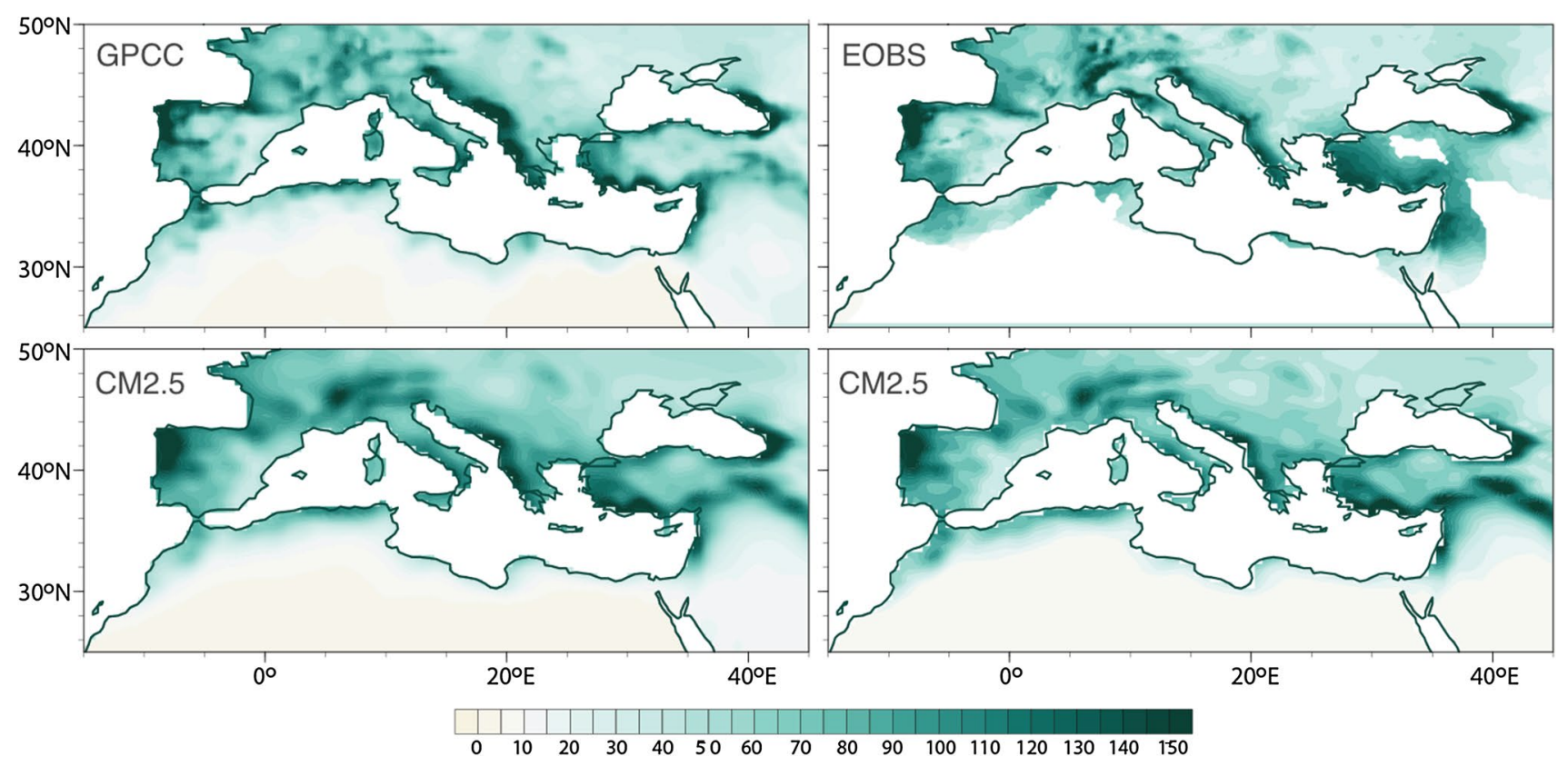

Fig. 2 (left) Seasonal (DJF) monthly precipitation rate over land areas for CM2.5 (mm/month) and observations (GPCC total monthly means for period 1901-2010). Both variables are shown at $0.5^{\circ} \times 0.5^{\circ}$ horizontal grid. (right) Seasonal (DJF) daily precipitation 90th percentiles $([\mathrm{mm} /$ day $] \times 10])$ for $\mathrm{CM} 2.5\left(0.5^{\circ} \times 0.5^{\circ}\right.$ horizontal

the Mediterranean climate. Both patterns are characterized with a meridional SLP dipole, except that the EA is southwardly shifted relative to the NAO. The characteristic anomalies have been shown (e.g. Trigo et al. 2002; Hurrell and van Loon 1997; Osborn et al. 1999; Seierstad et al. 2007; Vicente-Serrano and Lopez-Moreno 2008; Moore et al. 2011; Moore and Renfrew 2012) to modulate the mean airflow and location of storm tracks carrying moisture towards Europe and North Africa, influencing the hydroclimate in these regions. For example, a more positive phase of the low-frequency NAO variability and associated precipitation anomalies have been shown to significantly contribute to the last three decades of drying in the Mediterranean region (Mariotti and Dell'Aquila 2012). Although an origin of these changes is still a contestable issue (Kelley et al. 2012), it can potentially hinder or conversely amplify the signal of the anthropogenic climate change response. Therefore in the following part we investigate the skill of the model in simulating the low-frequency variability of NAO and EA and their impact on multidecadal climate changes in the North Atlantic and European sector.

By applying MSSA to the CM2.5 long (1000 year) control climate simulation, we isolate two coupled ocean-atmosphere components, which dominate the multidecadal scale regional climate variability. These components are extracted from the SLP and SST time series over the North Atlantic sector, and form physically grid) and observations (EOBS, $0.25^{\circ} \times 0.25^{\circ}$ resolution for 1960 1999 period). For model output, DJF monthly means (left) and DJF daily precipitation rate (right) from 900 to 999 years of control run are used

consistent, spatially coherent temporal patterns of variability. Time scales of the components are $\sim 45-48$ years (hereafter referred to as reconstructed component RC45) and 55-62 years (hereafter referred to as RC60). The detected oscillations are statistically significant (at the 95\% confidence level) and robust against changes of the time-lag parameter $(70<\mathrm{M}<100$, see Sect. 2.2).

The opposite phases of the first dominant component, RC45, is shown in Fig. 3a, b. Their spatial pattern, with a characteristic dipole-structure of SLP and a tripole-structure of SST, strongly resembles the observed NAO signature. The SLP pattern is centered in proximity to the Icelandic Low and Azores High, with its dipole counterparts being in strong antiphase. Time series of SLP reconstructed for these regions (Fig. 4, RC SLP $30^{\circ}-40^{\circ} \mathrm{N}$, RC SLP $60^{\circ}-70^{\circ} \mathrm{N}$ ), confirm a strong anti-correlation and explain up to $18 \%$ of decadal (smoothed with 15 year running mean filter) SLP variance. The three-lobe SST pattern is centered in the subpolar gyre, northern equatorial region and subtropical gyre. It manifests mostly along the Gulf Stream $\left(30^{\circ}-40^{\circ} \mathrm{N}, 70^{\circ}-50^{\circ} \mathrm{W}\right)$, where it explains up to $27 \%$ of the decadal SST variance.

The SST tripole corresponds with positive temperature tendencies in the southeastern United States and Scandinavia during the positive NAO phase (Fig. 3a), and negative temperature tendencies over Greenland and North Africa, which is consistent with observation-based studies (e.g. 
Fig. 3 Signature of the RC45 $(\mathbf{a}, \mathbf{b})$ and RC60 (c, d) RC60 component in the CM2.5 model, during positive/negative (left/right) phase. Shown are decadal change of SST $\left(\mathrm{C}^{\circ} /\right.$ decade, shaded) and SLP (hPa/ decade, contours). Components are derived from monthly means of the CM2.5 control run (1000 years)
Fig. 4 Time series of SLP (\%/ decade) and its reconstruction with the RC45 component, in the region of the Icelandic Low (NA $60^{\circ}-70^{\circ} \mathrm{N}$, blue ) and the Azores High. The variables shown are standardized to zero mean and unit variance (a)

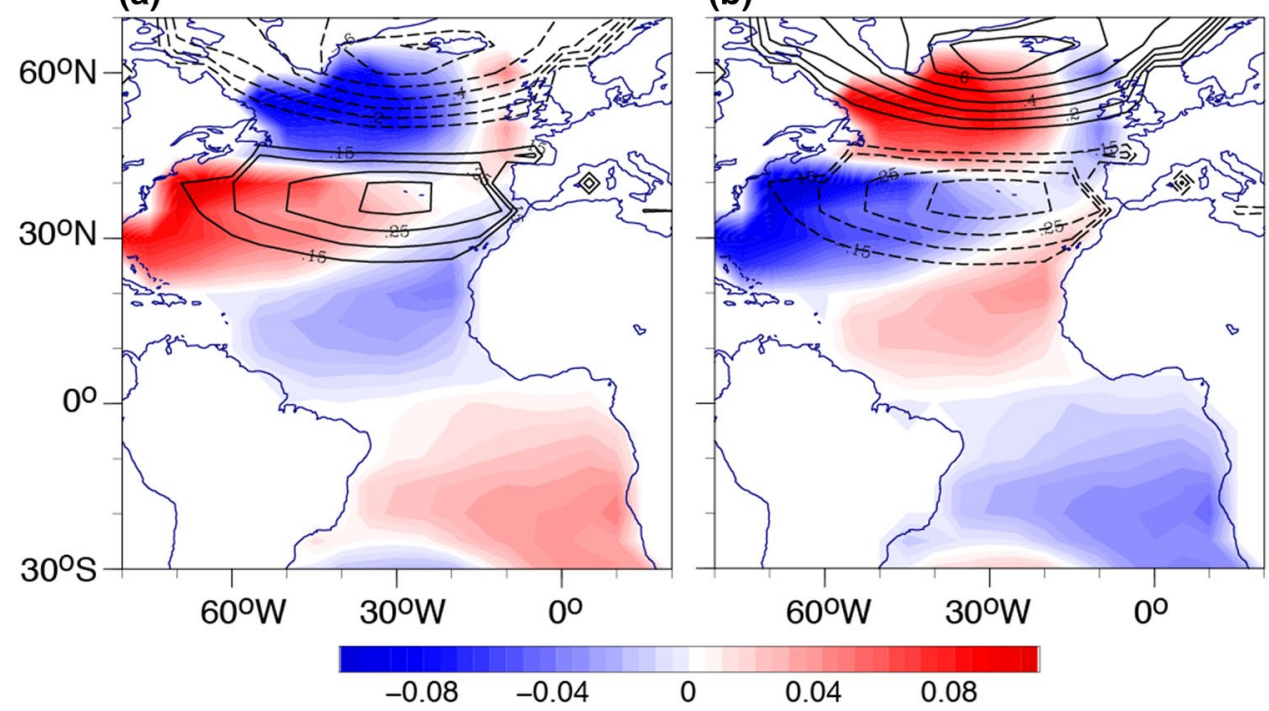

(c)
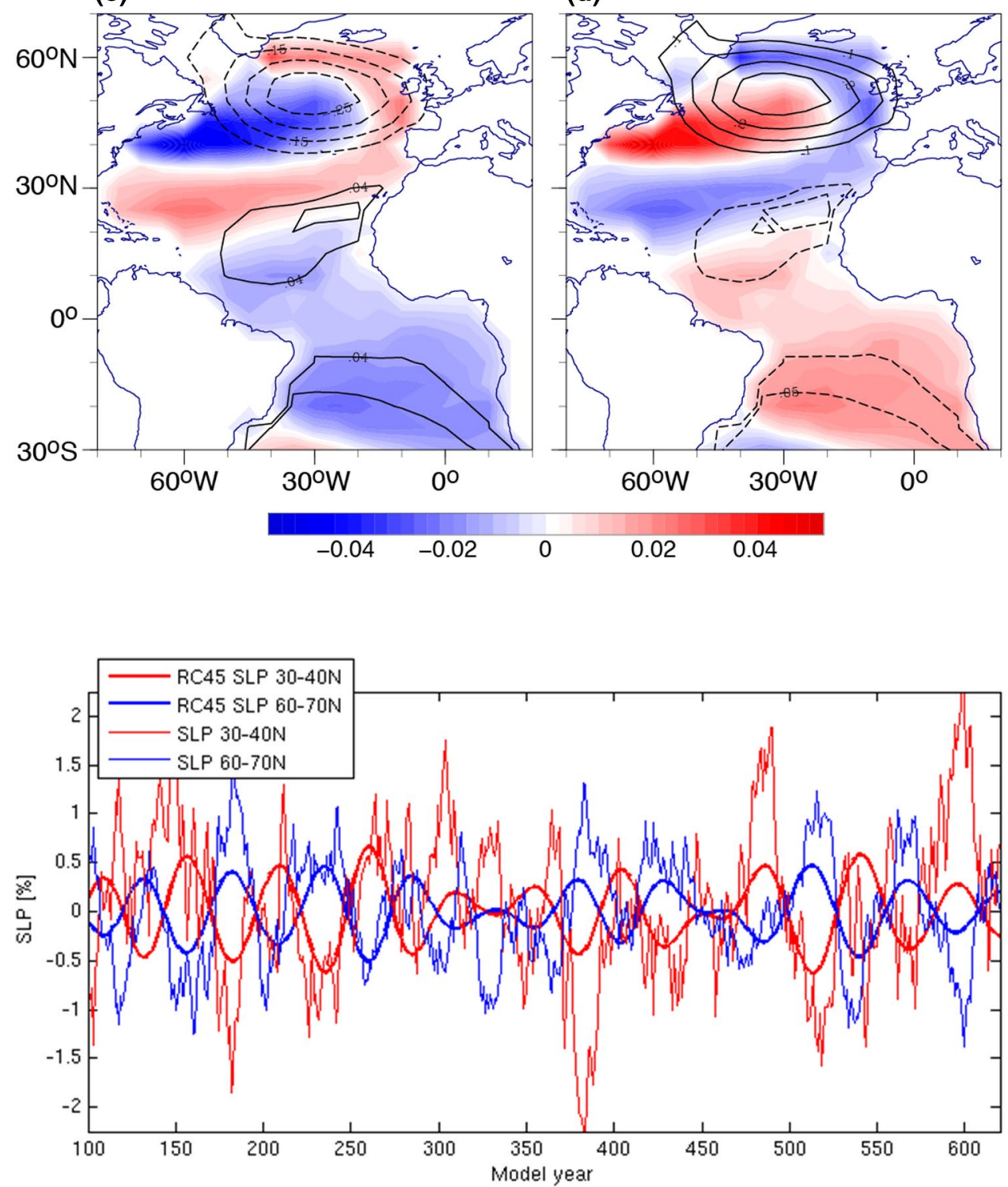
Hurrel et al. 2003). The physical mechanism linking the variations in the derived SLP and SST patterns has been investigated in numerous observational, modeling and theoretical studies of North Atlantic climate variability (Deser and Blackmon 1993; Kushnir 1994; Battisti et al. 1995; Delworth 1996; Seager et al. 2000; Selten et al. 1999). Consensus about the mechanism causing the reported SST changes has not been reached, and this issue is beyond the scope of this study.

The spatial patterns of the second dominant component of multidecadal variations in the North Atlantic sector, RC60, is depicted in Fig. 3c, d. The features of the simulated SLP anomalies closely resemble the observed East Atlantic pattern (Barnston and Livezey 1987; Woolings et al. 2010; Moore et al. 2011; Murphy and Washington 2001), with a SLP monopole in the vicinity of $52^{\circ} \mathrm{N}$, $22.5^{\circ} \mathrm{W}$ and a side-lobe (Moore et al. 2013) in the subtropical region. RC60 manifests mostly in the variability of SLP centered along $53^{\circ} \mathrm{N}$, where it accounts for $23 \%$ of the decadal SLP variance in this region. As Fig. 3c, d shows, the amplitude in the tropical and subtropical North Atlantic is smaller. However, standardized SLP changes (\%), as well as point-correlations between the regional RC60 SLP and the SLP field (not shown) indicate that RC60 contributes a comparable amount of variance in the mid-latitudes as in the subtropics. The reconstructed variations of SLP (RC60 SLP) in those two regions, consistent with observations, show an out-of-phase relationship. RC60 manifests also in the regional SST, resembling a horseshoe pattern. Its contribution to SST is smaller and concentrates mostly along the south-western flank of the mid-latitude SLP center. The maximum is located along the Gulf Stream northward extension, where RC60 SST explains up to $10 \%$ of the decadal SST variance.

The spatial features of the derived component correspond well with the modeling study of Ruprich and Cassou (2015), who also provided a physical explanation for ocean-atmosphere interactions in this area. The authors showed explicitly that low-frequency NAO and EA variations are tied to the Atlantic Meridional Overturning Circulation, which determines the multidecadal timescale of these atmospheric components.

An analysis of a long (4000 year) control run in the lower resolution GFDL CM2.1 model (not shown) corroborates spatio-temporal and physical fingerprints of the derived dominant components of multidecadal variability. It is also worth noting, that the SLP seesaw patterns, simulated with GFDL CM2.1 and other coarse resolution models (Ruprich and Cassou 2015), agree with observations to a relatively lesser extent than CM2.5 does. These spatial biases are most probably linked to the zonal bias of the mean mid-latitude circulation, which often characterizes these models. This fact highlights the importance of spatial resolution for simulating large-scale circulation variability, as it also affects the regional Mediterranean climate and weather.

The contribution of the low-frequency NAO- and EAtype variations may be particularly important, when investigating anthropogenic/long-term changes in atmospheric circulation over the North Atlantic and associated impacts on the Mediterranean climate. Therefore in the following section we will analyze the physical link between the NAOand EA-type components and the Mediterranean winter hydroclimate, derived from the CM2.5 simulations.

\subsection{Impact of multidecadal-scale atmospheric circulation variability on the European and Mediterranean hydroclimate}

CM2.5 has been shown to have a high skill in simulating the dominant components of the observed atmospheric circulation over the North Atlantic. Therefore in this section we wish to validate the $\mathrm{CM} 2.5$ skill in capturing the impact of these components on the Mediterranean winter hydroclimate. For this purpose we use a MSSA analysis, which allows us to extract spatio-temporal patterns of precipitation anomalies associated with the derived large-scale circulation features. Regression analysis, applied to seasonal (DJF) SLP, wind vectors, vorticity and precipitation, will corroborate the suggested physical linkage.

Figure 5a shows that the anomalous atmospheric flow over the North Atlantic, which describes RC45, manifests also across Europe and the Mediterranean region. A corresponding sharp SLP gradient and westerly flow in the mid-latitudes tilts over the land towards the northeast. Cyclonic circulation anomalies in the mid-latitudes are spread towards the British Isles and Scandinavia, while anticyclonic anomalies in the subtropics extend towards the western Mediterranean and Southern Europe. This circulation pattern also corresponds with vorticity (Fig. 5a) and precipitation (Fig. 6a) anomalies, depicted as zonal and opposite-sign bands on the flanks of the SLP cells. The subtropical band of anomalous vorticity and precipitation is most pronounced over the North Atlantic, but it extends further northeast from the coasts of northwestern Africa and southern Iberian Peninsula towards the Balkan region and the Black Sea.

An apparent correlation (Fig. 5a) between positive (negative) SLP, negative (positive) vorticity anomalies and drying (wettening) tendencies indicates a physically consistent link, pointed out previously by Trigo et al. (2002). The authors examined the impacts of synoptic time scale NAO variability and found a very similar anomalous precipitation pattern for the high latitudes and subtropics. They pointed out that modulation of the meridional circulation cells adjusts vorticity fields and associated low-level 

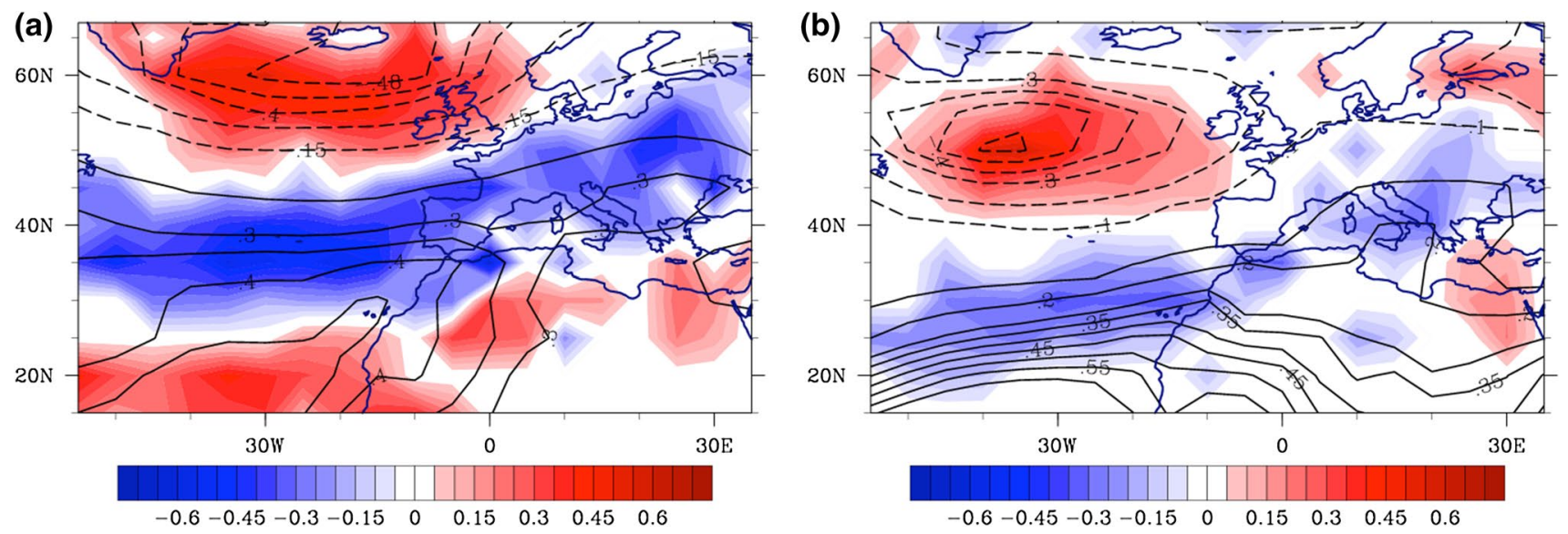

Fig. 5 Regression of standardized winter fields of SLP (contours), vorticity a for RC45 SLP and b RC60 time series component. Regression coefficients are shown, when significant on $95 \%$ level (for SLP and vorticity)

(a)
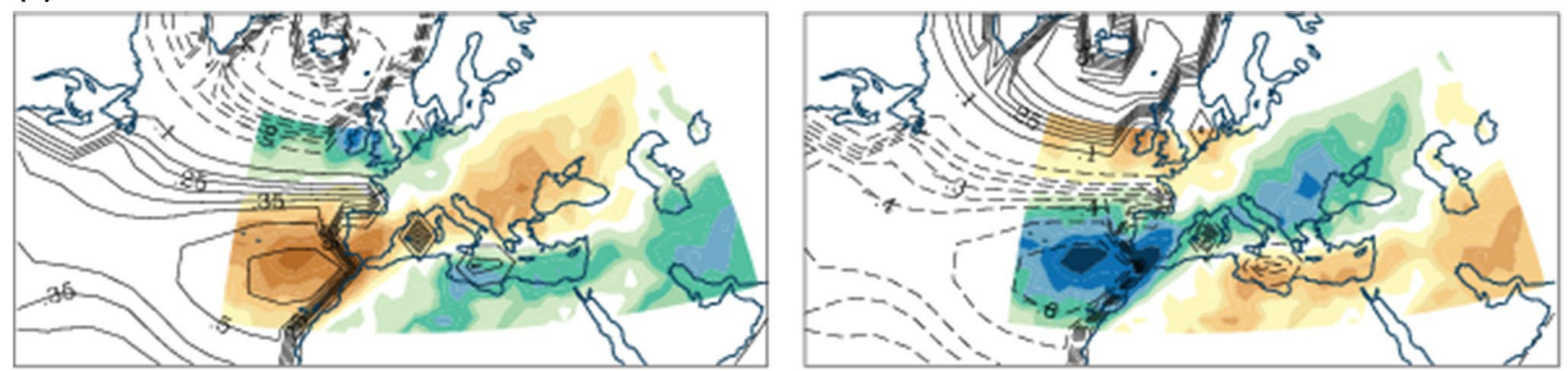

(b)
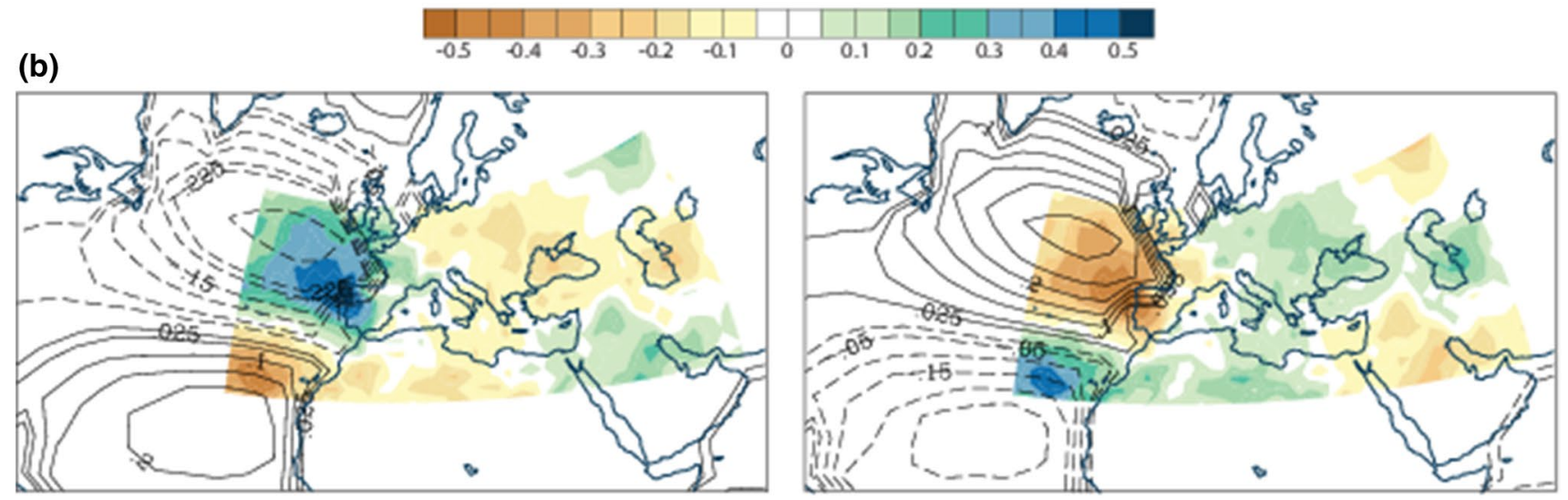

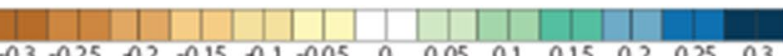

Fig. 6 Signature of a RC45 and b RC60 component, represented with SLP (contours, solid are postive, stippled are negative) and PRECIP (shaded) anomalies in CM2.5 model. Shown are trend coefficients of SLP and PRECIP anomalies, standardized to unit variance (\%/decade)

convergence (divergence), which facilitates condensation of precipitable water and in effect leads to anomalous precipitation.

Figure 6a describes in spatial detail the linkage between modulated with RC45 meridional SLP cells over the North Atlantic and precipitation changes in the Mediterranean. A typical NAO-type SLP structure (as in Fig. 5a) is clearly accompanied by a meridional contrast in precipitation anomalies over most of the Mediterranean. An intensified (weaker) SLP gradient corresponds with negative (positive) precipitation anomalies in the Iberian Peninsula and Strait of Gibraltar, which extend across the northern 
Mediterranean up to the west coast of the Black Sea. In contrast, precipitation anomalies located to the south of this band (northeastern coast of Africa, Israel, and Syria) show opposite tendencies. Intermediate phases (not shown) between these two RC45 phases feature an almost neutral SLP state and much weaker precipitation anomalies. The latter ones, located in the northern subdomain are shifted to the northeast, while those in the southern part are shifted southwestward.

The simulated multidecadal NAO-type circulation changes have the most profound impact on precipitation (Fig. 6a, b) over the Iberian Peninsula and the west coast of the Black Sea. The RC45 component (Fig. 7) explains up to $26 \%$ of decadal precipitation variance in the southwestern part of the Iberian Peninsula. These results are consistent with findings of Mariotti Dell'Aquila (2012), who show that the NAO explains over $30 \%$ of decadal precipitation variability in DJF, as observed in Spain, Morocco, Italy and the Balkans. Impact of R45 in the southeastern Mediterranean (northeastern flanks of Egypt and Israel) is less pronounced, explaining up to $12 \%$ of variance (Fig. 7). The regional time series (Fig. 7) for the northwest and southeast parts of the Mediterranean depict a strong negative correlation between these two regions, associated with the derived atmospheric circulation pattern. This feature is consistent with previous observational studies, investigating the impacts of the NAO on European hydroclimate (Trigo et al. 2002; Hurrell and van Loon 1997; Osborn et al. 1999; Kelly et al. 2011).

The second component (RC60), resembling the atmospheric Eastern Atlantic-type pattern, modulates the circulation and hydroclimate in the Mediterranean analogously to the NAO-type component (RC45). The action of RC60 is shifted southward, resulting in its impact on Mediterranean also being shifted and less pronounced, than in RC45. A regression of SLP and vorticity fields onto the RC60 SLP index, shown in Fig. 5b, depicts the spatial pattern of RC60's influence over Europe and the Mediterranean. The figure shows that the anomalous circulation pattern in RC60 (and associated anomalous vorticity and divergence) extends from the subtropical North Atlantic towards the southwestern flanks of the Mediterranean and tilts northeast towards the Italian and Balkan Peninsulas.

Associated with this pattern are opposite-sign precipitation anomalies between the Iberian Peninsula and the west-central North Africa region (Fig. 6b). Negative (positive) SLP anomalies, centered at $53^{\circ} \mathrm{N}$, correspond with positive (negative) precipitation anomalies in the Iberian Peninsula and Strait of Gibraltar. RC60 has the most pronounced impact in this region (i.e. over the northwestern part of the Iberian Peninsula), explaining up to $24 \%$ of the decadal precipitation variance. Conversely, positive (negative) SLP anomalies in the subtropics correspond with drying (wettening) tendencies in the southwestern Mediterranean (i.e. Morocco and Tunis). However, RC60 impacts these regions to a much smaller extent. These precipitation anomalies spread further, across the central Mediterranean towards the Balkan Peninsula and Turkish coasts, consistent with the pattern and smaller magnitude of the anomalous SLP and vorticity fields. Observational studies have paid less attention to the role of this pattern, likely due to the insufficiently long data required to study its low-frequency changes. Nevertheless, several studies have suggested a non-negligible impact of the EA pattern on the Mediterranean and western European climate through its modulation of the NAO location.
Fig. 7 Time series of DJF precipitation anomalies (normalized to unit variance and smoothed with 15-year running mean filter) and its reconstruction with RC45 component, for the Azores High and Eastern Mediterranean (reg1: $31-37^{\circ} \mathrm{N}$, $25^{\circ}-15^{\circ} \mathrm{W}$ and reg2: $31^{\circ}-35^{\circ} \mathrm{N}$, $24^{\circ}-34^{\circ} \mathrm{E}$ respectively)

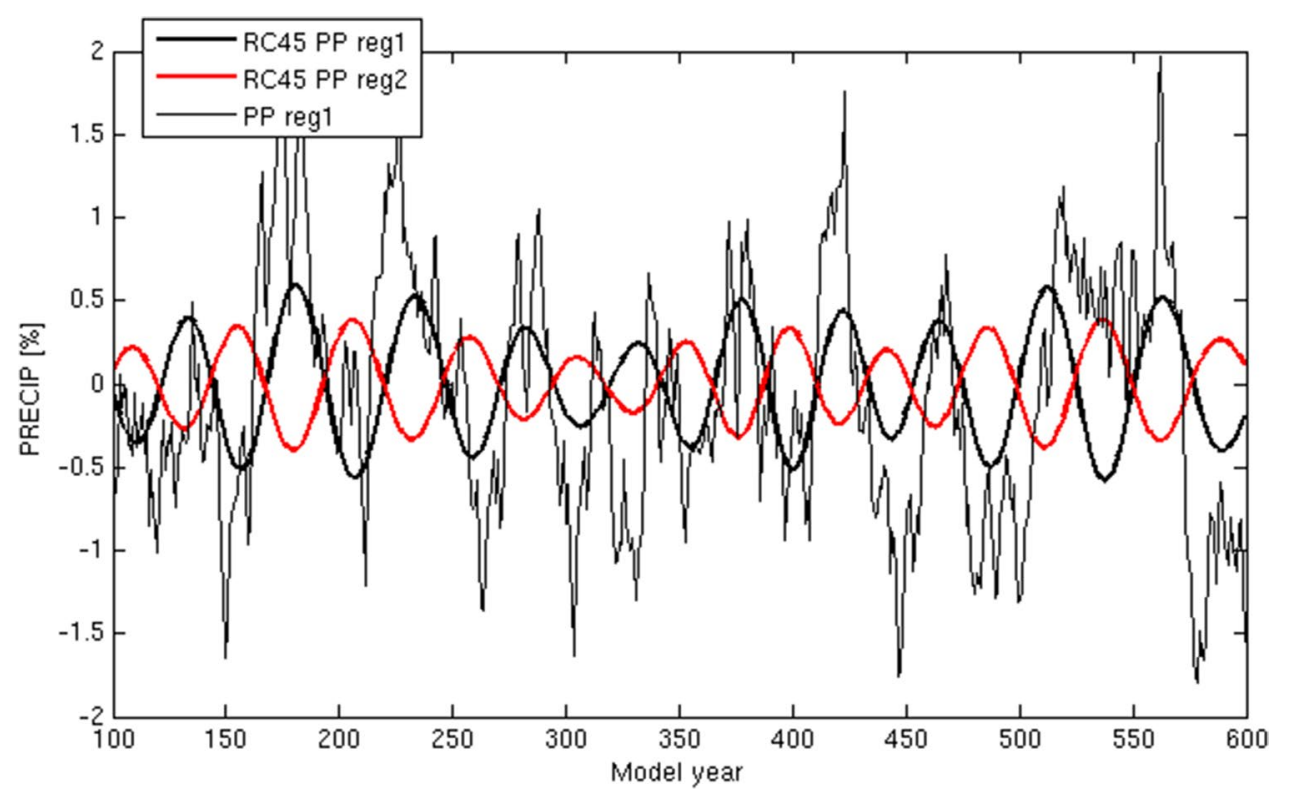


Overall, in this section we have shown that the CM2.5 model simulates realistic features of the mechanisms governing Mediterranean winter hydroclimate. They are diagnosed here in the derived large-scale circulation components that dominate multidecadal climate variability in the North Atlantic sector. Both NAO- and EA-type components substantially modulate the mean atmospheric flow over Europe and North Africa, and consequently the mean precipitation in these regions. The simulated fingerprints of these components as well as their impacts on European and Mediterranean hydroclimate are consistent with observational, reanalysisderived, and some modeling studies. An additional finding coming from our analysis relates to the origin of the multidecadal components. This can not be inferred from the instrumental records due to their limited length. The long (1000 year) control run of CM2.5 shows clear evidence that these multidecadal changes can originate purely from unforced, internal processes of the climate system. As the derived components have a pronounced influence on the long-term changes of the Mediterranean climate, their presence should be taken into account while analyzing, detecting and attributing signals of climate change response.

\section{Mean climate change projections, large-scale and regional scale perspective}

In this section we analyze the projection of the Mediterranean mean and extreme hydroclimate in the RCP8.5 scenario. Future mean climate is to large extent associated with changes in the mean ambient flow. Therefore, the derived mean changes will be shown and discussed in the context of large-scale climate conditions over the North Atlantic and European sectors. Extreme precipitation may be affected both by the increase of atmospheric vapor, as well as large-scale circulation changes. Therefore, changes of extreme precipitation in this region are not necessarily expected to closely follow the thermodynamic constraint, based on the Clausius-Clapeyron relation, neither to scale with the mean climate change. Changes in precipitation extremes are analyzed separately, using an approach of relative thresholds (i.e. percentiles and return values, estimated based on the GEV theory). The following two sections focus on the winter (DJF) Mediterranean hydroclimate, derived for the period 2061-2099 (future), relative to the present period 1961-1999 (present). Fractional changes (\%) are also computed with respect to the present period [(future minus present)/present].
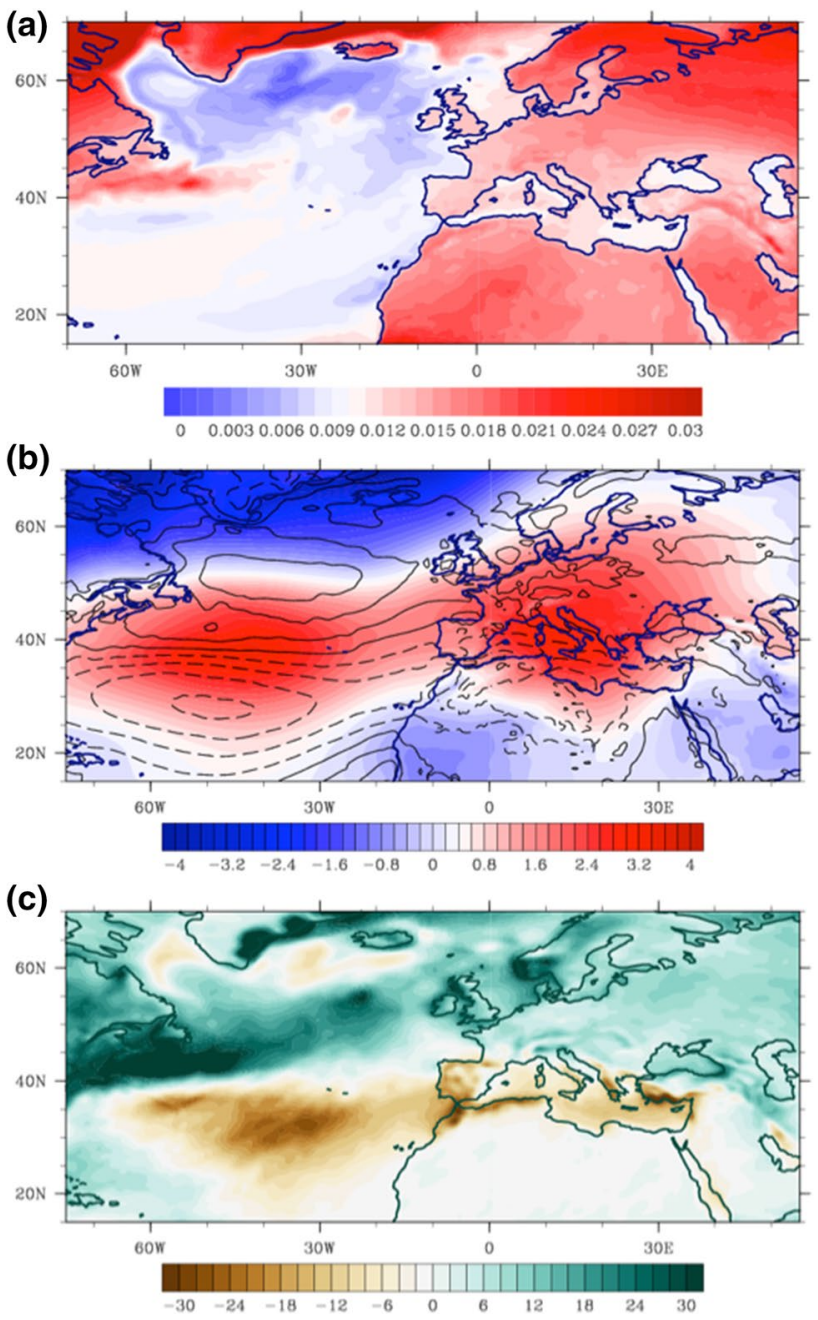

Fig. 8 Changes projected for winter (DJF) monthly a fractional change of surface temperature $(* 100 \%)$, b sea level pressure $(\mathrm{hPa}$, color shaded) and zonal wind component (contours from -2.5 to $2.5 \mathrm{~m} / \mathrm{s}$ ), c total precipitation rate (mm/month) by $2061-2099$, compared to the present (future, 2061-2099 minus present 1961-1999 climate)

\subsection{Large-scale circulation and mean precipitation changes}

Figure 8 shows maps of projected fractional changes in surface temperature, changes in atmospheric circulation and precipitation for the period 2061-2099. The main features depicted here resemble the typical fingerprint of a global warming response, featuring a poleward shift and intensification of meridional circulation cells. This is indicated by a strengthening of the meridional SLP gradient between the subtropics and mid-latitudes (the Icelandic Low). Consistent with these changes is a strengthening of westerlies/ easterlies present on the poleward/equatorward flanks of the intensified subtropical high. Poleward expansion of the Hadley Cell has already been shown in many earlier studies 
to be a robust global-warming response, in turn associated with a poleward shift and eastward extension of mid-latitude westerlies and storm tracks (Lu et al. 2007; Yin 2005; Bengtsson et al. 2006; Wu et al. 2011). Another robust feature of projected SLP changes, seen already in CMIP3 and CMIP5 simulations (Giorgi and Lionello 2008; Giorgi and Coppola 2007; AR5, IPCC 2007), is a maximum centered over the central Mediterranean. Strengthening of anticyclonic circulation in this region will presumably increase stability and create conditions less prone for the generation of cyclones (Giorgi and Lionello 2008). Seager et al. (2014) argued that this strong anomaly localized over Italy and the Balkan Peninsula, seen also in a low-level high, increases subsidence and mean flow moisture divergence leading to strong drying in the region.

Increasing warming contrast between land and ocean, present even in much earlier versions of general circulation models (Manabe et al. 1990, 1991), could amplify the drying tendencies in the Mediterranean region. Derived fractional changes in surface temperature (Fig. 8a) show a stark contrast between rapidly warming land and slowly warming ocean with minima located along the cold currents: Labrador and Canary Currents. The western Mediterranean (Northwest Africa, Iberian Peninsula) is largely affected by moisture transport from the ocean, limited by the cold and less-evaporative circumfluent Canary Current. Therefore, disproportional warming between these land and ocean regions, accompanied with constrained (with muted warming and evaporation) ocean moisture transport, will likely decrease relative humidity and precipitation (Fasullo 2010; Joshi et al. 2007; Byrne and O'Gorman 2015) in the western Mediterranean coasts.

Projected precipitation changes (Fig. 8c) are in general agreement with the above-described circulation and temperature changes. The northward shift and strengthening of the North Atlantic mean airflow corresponds well with the large-scale poleward shift of precipitation. Negative precipitation anomalies are centered between $30^{\circ}$ and $40^{\circ} \mathrm{N}$, consistently with the subtropical high and associated divergence and trade winds in this region. These conditions spread eastward, promoting more stable conditions and reduced precipitation across most of the Mediterranean.

Projected fractional changes in precipitation (Fig. 9c) show two maxima. The first one is located in the semi-arid Northwest Africa, where precipitation is reduced up to $50 \%$ by the end of the twenty-first century. The second one is concentrated in the central and eastern Mediterranean, i.e. the Balkan Peninsula and a large fraction of Turkey $(\sim 25 \%)$, where changes reach to $-25 \%$. The pronounced and statistically significant (at the 5\% level) decrease expands also over other regions, e.g. the Iberian Peninsula (up to 20\%), or the Italian Peninsula ( 10\%), which have in general relatively large mean precipitation ratios. In contrast, the northern flanks of the Mediterranean region experience a transition towards "wetter" conditions prevailing over the mid-latitudes. Positive changes occur in northern Italy, Slovenia, and the Black Sea region.

This strong bipolar behavior is depicted in Fig. 9, which shows the temporal evolution of precipitation changes in the northern and southern subdomains of the Mediterranean region. Figure $9 \mathrm{a}$ shows a general reduction in winter precipitation for the whole Mediterranean region. Yet in the twentieth century and in the beginning of the twenty-first century, this time series shows pronounced multidecadal variability. A gradual decrease starts dominating the signal in the 2030s/2040s. Figure 9b shows a regional contribution to the signal, with a strong, downward trend apparent in the southern subdomain from the mid twentieth century. In contrast, changes in the northern Mediterranean show weak upward tendencies and strong multidecadal-scale variability prevailing for most of this time.

These features are consistent with the large-scale response of the hydrological cycle to global warming. Thermodynamic factors i.e. increasing atmospheric water vapor in a warming climate (Held and Soden 2006; Chou et al. 2009) are expected to intensify the hydrological cycle, leading presently dry subtropical regions into drier conditions and presently wet mid-latitudes into wetter conditions. For the semiarid Mediterranean region these changes can be even more intensified by dynamic factors such as a poleward expansion of the Hadley Cell and the associated northward shift of storms (Yin 2005; Lu et al. 2007; Wu et al. 2011).

Figure $9 \mathrm{a}, \mathrm{b}$ also shows that the evolution of reanalyzed and observed precipitation (20CR and GPCC) is quite different from the simulations. Observation-based changes are several times larger than the projected response. Observed tendencies for the second half of the twentieth century indicate a very strong decrease, and also show much greater variability, especially on multidecadal time scales. Additionally, a strong decrease is apparent in both southern and northern domains of the Mediterranean. This is consistent with the observed (Kelley et al. 2011) and simulated (in CM2.5) NAO fingerprint and different from the climate change fingerprint simulated in CM2.5. Therefore the observed decrease could be indicative of the dominating impact of internal variability in the current state of climate, which is consistent with our modeled results.

\subsection{Large-scale circulation and daily precipitation changes in the Mediterranean}

Mid-latitude storm systems, governed by the mean flow over the North Atlantic, last on average 4-8 days and carry large amounts of moisture. Therefore, they have a pronounced impact on daily extreme rainfall. Associated 


\section{(a)}

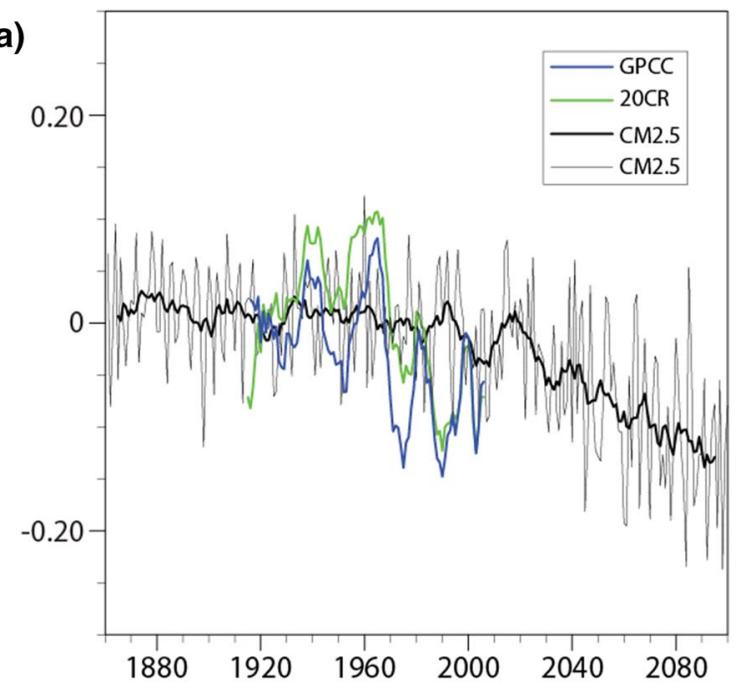

(c)

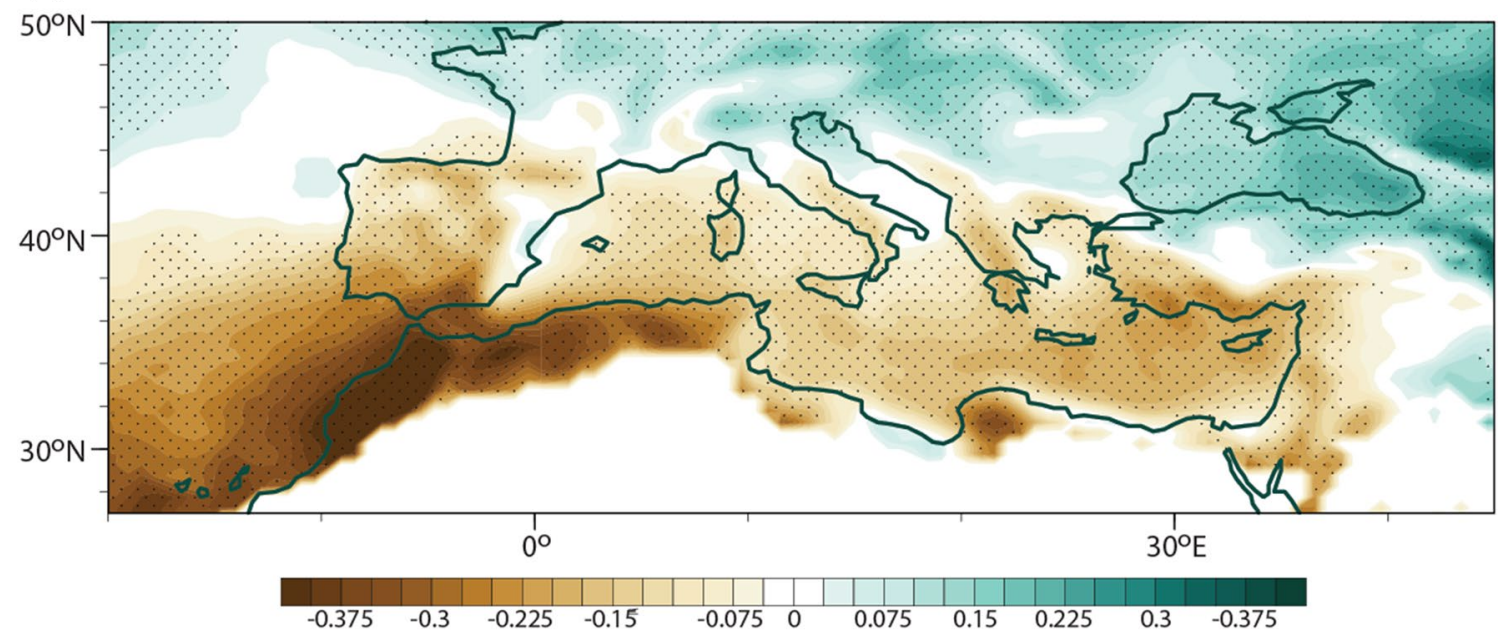

Fig. 9 Changes in simulated and reanalyzed/observed seasonal (DJF) mean total precipitation rate $(\mathrm{mm} / \mathrm{month})$ for the Mediterranean region. Time series are calculated with respect to the present (1961-1999) for the a $30-45^{\circ} \mathrm{N}, 10^{\circ} \mathrm{W}-40^{\circ} \mathrm{E}$; b southern $(\mathrm{S}$, $\left.28-38^{\circ} \mathrm{N}, 10^{\circ} \mathrm{W}-40^{\circ} \mathrm{E}\right)$ and northern $\left(\mathrm{N}, 38-47^{\circ} \mathrm{N}, 10^{\circ} \mathrm{W}-40^{\circ} \mathrm{E}\right)$ subdomains. Shown are time series of a CM2.5 (black bold and thin line), twentieth Century Reanalysis (20CR, green) and GPCC (blue);

storm surges pose a serious threat to coastal regions, with topography and circumfluent ocean currents potentially amplifying their impact. These processes can only be explained in a coupled atmosphere-ocean high-resolution modeling framework. This can be seen to some extent in the seasonal (DJF) precipitation maps (Fig. 8c), which show strong projected increases for the western North European coasts (UK, Norway) and decreases concentrated along the western coasts of the Mediterranean (north-western Morocco, Algeria and the south-western coast of Turkey, the Iberian and Balkan Peninsula). However, changes in daily precipitation could have an even larger magnitude and impact. Hence in this section

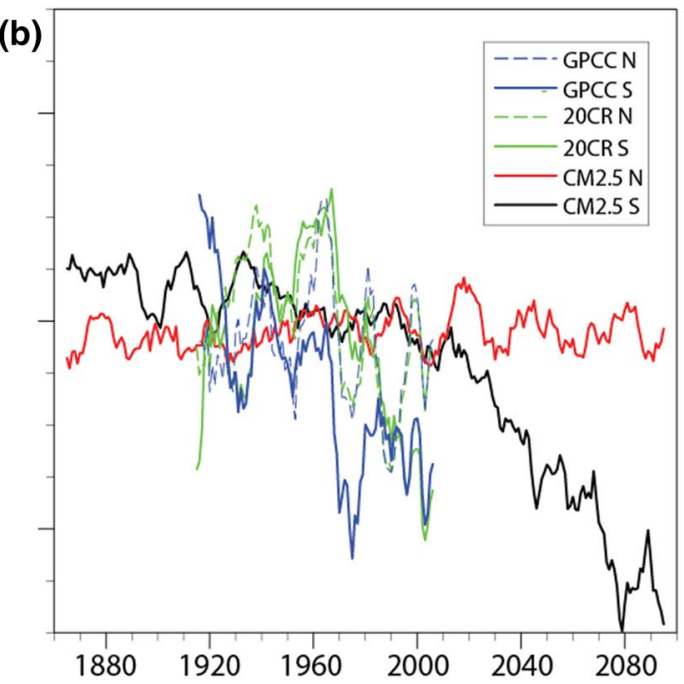

b CM2.5 (red, black), twentieth Century Reanalysis and GPCC for S and $\mathrm{N}$ regions. All time series, except CM2.5 (black thin line) in a, are smoothed with 10-year running mean filter. All data sets except GPCC provide data for the land and sea regions. $\mathbf{c}$ Fractional changes $(* 100 \%)$ in projected seasonal (DJF) mean precipitation by $2061-$ 2099 , for regions with daily ratio larger than 0.1 ( $\mathrm{mm} /$ day). Changes significant at the $5 \%$ level are marked with black dots

we focus on projected changes in daily precipitation extremes.

Figure 10 shows projected fractional changes in the 10th and 90th percentiles of winter (DJF) daily precipitation ratios for the North Atlantic, Europe and North Africa, up to the end of the twenty-first century. Spatially coherent, large-scale features of derived precipitation changes are physically consistent with the accompanying seasonal changes in atmospheric circulation and SST, as well as the corresponding increase in land-sea temperature contrast (Xie et al. 2010). The projected changes in low percentiles (Fig. 10a) of precipitation show a pronounced decrease in many regions. Over the North Atlantic this decrease 

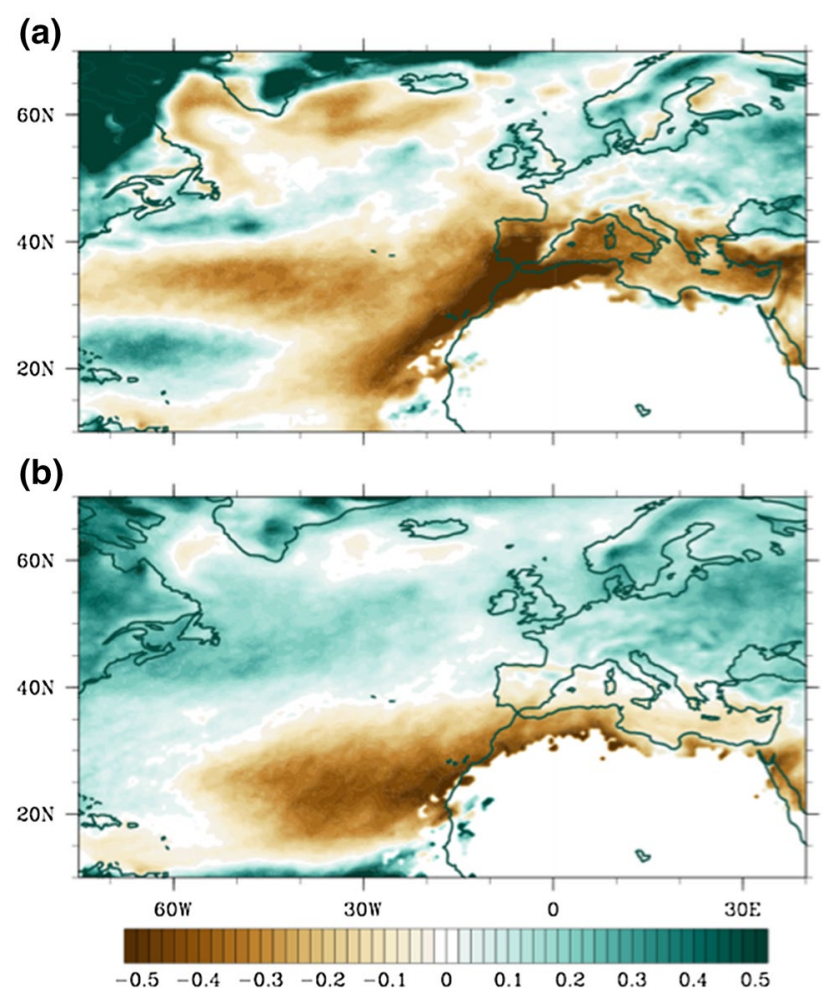

Fig. 10 Fractional changes in projected for winter (DJF): a 10th and b 90 th percentile of daily precipitation rate (*100\%), by 2061-2099, compared to 1961-1999, for regions with 50th percentile larger than $0.1(\mathrm{~mm} /$ day $)$

is collocated with divergent anomalies in the subtropics, south of the Gulf Stream, and a relatively low ratio of SST increase. Wetting tendencies along the warm Gulf Stream and drying tendencies along the cold Labrador and Canary Currents together form a spatially coherent pattern, which is physically consistent with intensifying meridional cells, trade winds and their impact on the wind-driven North Atlantic gyre. Strengthened trade winds, corresponding stronger upwelling, and cooling SSTs along the Canary Current promote even more stable and dry conditions in the neighboring semi-arid regions.

These regions, particularly the Iberian Southeast and the NW African coast, have extremely low rainfall, which makes them very vulnerable to precipitation changes. As Fig. 10a shows, the most remarkable fractional changes are seen in Northwest Africa, the southern Iberian Peninsula and along the circumfluent Canary Current, where the decrease exceeds $50 \%$. These tendencies are apparent for both lower and higher (5th, 15th, and 50th percentiles) percentiles.

The decrease depicted here extends over most of the Mediterranean region, with secondary maxima located over the Italian and Balkan Peninsula and southern Turkey. The severe changes in the 10th percentiles shown here imply a higher probability of drought conditions and longer dry spells. Similar conclusions were drawn from the AGCM projections of Kitoh and Endo (2016), who analyzed seasonal (DJF) maximum numbers of consecutive dry days. These authors have also found a large increase in this index, reaching 50\% along the cold Canary Current, the northwest African coast, and also the eastern Mediterranean.

Changes in the 50th percentiles (Suppl. Fig. 1) show a similar pattern for the Mediterranean region. The magnitude of changes is smaller and reaches a maximum along the Northwest African coast (40\%), south Iberia, the Balkan Peninsula and the southern coast of Turkey (up to $25 \%)$.

Projected changes for the 90th percentiles of daily precipitation (Fig. 10b) show a different spatial pattern, indicative of different factors playing a role. Positive anomalies centered over the North Atlantic mid-latitudes and negative anomalies in the eastern subtropics, resemble a pattern of storms supplying moisture to the northernmost flanks of the Mediterranean and Europe. Compared with lower percentiles (50th), the increasing tendencies extend farther south toward the northern regions of the Iberian and Italian Peninsulas, the Adriatic Sea and the neighboring Croatian coast as well as the northern part of Turkey. Negative tendencies persist only in northern Africa.

Figure 11 shows projected changes in three precipitation indices by the end of the twenty-first century. These are seasonal 1- and 5-day maxima of daily precipitation, and return values for a 10-year return period, derived through asymptotic GEV theory approximation. In general, the geographical pattern of the projected changes for R5d and $\mathrm{R} 1 \mathrm{~d}$ is similar to that derived for seasonal mean changes (Fig. 9). However, the fraction of the area with positive tendencies is larger and expanded southward. The pattern for the R5d index (Fig. 11a) features a distinct contrast between the northern and southern domains, with positive changes in the former and negative changes in the latter. R5d is projected to increase by $10-15 \%$ in the central part of Iberian Peninsula, the French coast, and almost the whole Italian Peninsula. R5d has a regional maxima increase of $\sim 30 \%$ in the Croatian coast. Changes in many of these regions (e.g. the African coast) are statistically significant. Projected changes in R1d closely resemble the previous pattern, with positive changes being more prominent, and the north-south contrast shifted southward. For example: Wetting tendencies expand in the Iberian Peninsula and reach a $25 \%$ increase there, $20 \%$ in Italy, and become significant even at the $5 \%$ level. Positive changes cover Corsica and the whole Balkan Peninsula. Decreasing changes in the southern subdomain cover less area, have smaller magnitude and are less significant.

Changes in the upper limits of the extremes, approximated by GEV theory, emphasize the previously indicated 
Fig. 11 Fractional changes $(* 100 \%)$ for winter projections (DJF) 2061-2099: a R5d, 5-day maximum precipitation total, b R1d, 1-day maximum daily precipitation total; c 10-year return values. Return values are approximated with the GEV theory, using daily precipitation maxima of each DJF season. Changes in $\mathbf{a}$ and $\mathbf{b}$ passing the Wilcoxon Signed rank test at the $10 \%$ significance level are marked with black dots

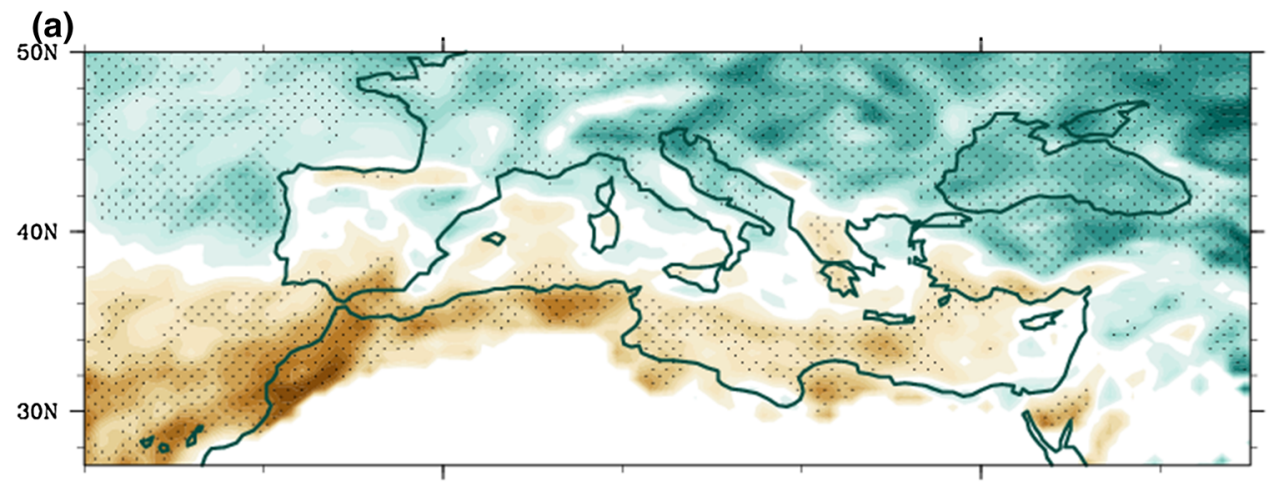

(b)

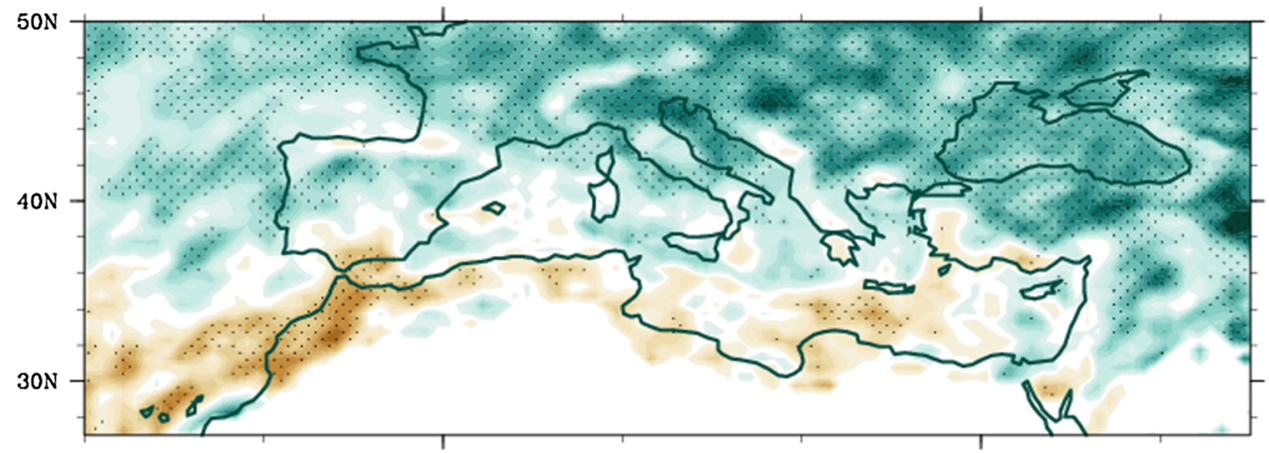

(c)

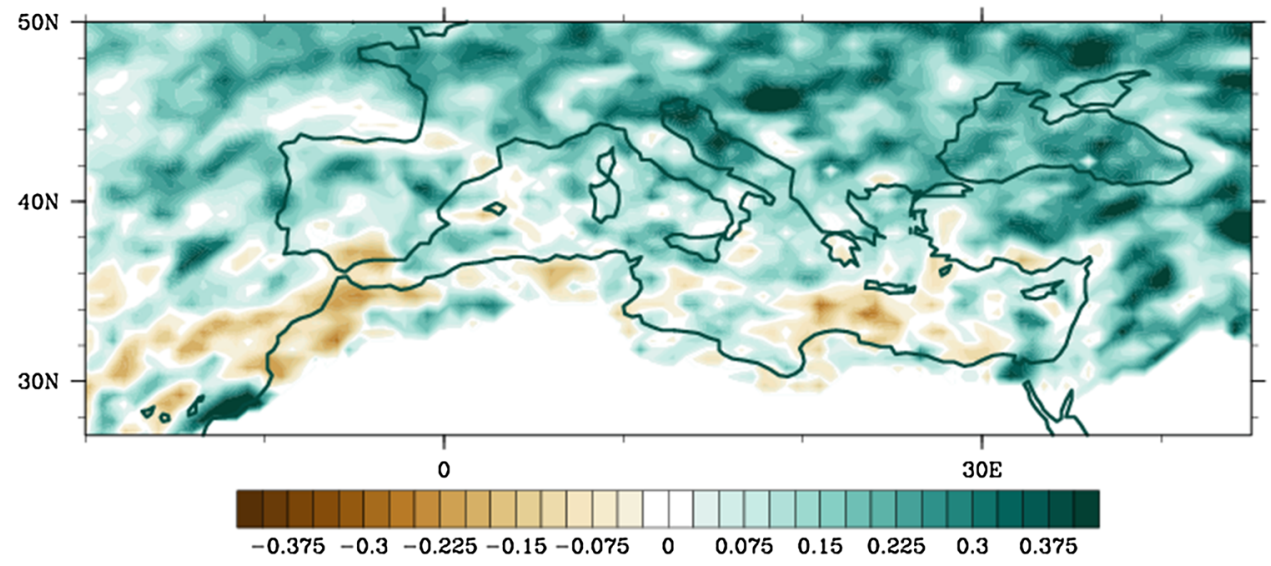

"wetting" tendencies. Fractional changes in 10-year return values (Fig. 11c) show an expanded pattern of heavy rainfall increase, notably covering the whole Iberian Peninsula except its semi-arid Southeast. The decrease persists along the Northwestern African coast. Nevertheless it is worthy to note that the GEV approximation in this region didn't pass the Kolmogorov-Smirnov goodness-of-fit test, indicating a lower reliability of the derived estimation.

Consistent with the 1-day maxima, the most considerable increase (up to 35\%) occurs in the northern regions of Spain, the Alps, the Adriatic Sea and the Black Sea regions. This may pose a serious threat for the coastal parts of those regions, which are most sensitive to atmospheric conditions, and where rainfall is usually much higher than over inland regions (e.g. Black Sea). In some regions (e.g. maximum in the Iberian Peninsula, east coast of the Black Sea, where the GEV did not pass goodness of fit test) the cumulative distribution function approximated using the GEV is larger than the fitted data, suggesting that the derived changes in heavy rainfall RVs could be overestimated.

Tendencies of the here derived precipitation extremes show general agreement with the CMIP3 and CMIP5 multimodel assessments (Toreti et al. 2013; Kharin et al. 2013). Toreti et al. (2013), who used eight high-resolution GCMs, found increases in 50-year General Pareto Distribution Return Values in winter. Kharin et al. (2013) found similar tendencies for 20-year GEV Return Values of annual daily precipitation in CMIP5 multi-model ensemble. A study of 
Kitoh and Endo (2016), which employed a 20-km resolution AGCM, shows that heavy precipitation events will intensify despite mean drying tendencies in the Mediterranean. Downscaling estimations of Paxian et al. (2015) indicate bipolar tendencies for the future winter season, including wetting and drying tendencies over the northern and southern Mediterranean, respectively. At the same time, the authors show that precipitation extremes will intensify over large areas and even in the regions with strong mean drying (e.g. southern Europe and Turkey). These high-resolution studies corroborate our results, and underline an increasing risk of hydro-meteorological type disasters especially in the coastal zones of the Mediterranean.

\section{Summary and conclusions}

Winter Mediterranean hydroclimate is shaped to a large extent by a complicated topography, air-sea interactions, and large-scale tropical and mid-latitude atmospheric circulation. Consequently it exhibits spatial complexity and pronounced temporal variability across daily-to-multidecadal time scales. These features were till now posing a challenge to the current CMIP5 generation of models. Either horizontal resolution of these models and/or their representation of the physical mechanisms are not satisfactory to skillfully represent winter climatology of the Mediterranean region.

In this article, we tackled the question of how large changes of both mean and extreme winter Mediterranean precipitation may be at the end of the century. A stateof-the-art high-resolution general circulation model was applied to simulate both pre-industrial states and future climate scenarios. This study shows that the CM2.5 highresolution model $\left(\sim 0.5^{\circ}\right)$ produces not only refined regional scales of derived Mediterranean climatology, but also more realistic large-scale atmospheric circulation features, which influence the regional climatology. Representation of the mean flow over the North Atlantic is much improved in CM2.5, compared to the low-resolution CM2.1 model, exhibiting a pronounced zonal bias. Substantial reduction of this bias in CM2.5 highlights importance of high horizontal resolution, which enables more realistic representation of land-sea contrast, and consequently improves the representation of the jet stream and mean atmospheric circulation. Corresponding to this improvement, we obtain a better representation of climatological precipitation, which includes the reduction of positive and negative biases in the Mediterranean region (for the Iberian Peninsula and Balkan Peninsula respectively). The improved representation of large-scale ambient flow over the North Atlantic, which largely controls the storm tracks location, likely contributed to the realistic representation of the Mediterranean daily precipitation extremes (e.g. 90th percentile of daily precipitation in DJF).

CM2.5 also reliably simulates variability of the largescale circulation (i.e. NAO- and EA-type), which impacts winter Mediterranean hydroclimate. Our analysis corroborates some of the previous studies, which highlight a dominant effect of the NAO pattern (Kelley et al. 2012; Trigo et al. 2004; Mariotti and Dell'Aquilla 2012). For example Kelley et al. (2012) argued that past three decades of drying over the Mediterranean are to a large extent caused by the negative phase of the multidecadal NAO variations.

Previous generations of models (CMIP3 and CMIP5) proofed their capability to simulate the observed atmospheric large-scale circulation patterns over the North Atlantic and Europe, e.g. the NAO, active on time scales spanning from synoptic to decades. In this research, we used a long CM2.5 control run (1000 year) to show that this variability exists on multidecadal time-scales, can originate purely from internal climate variations, and have a sufficiently large impact to modulate (either hinder or amplify) the anthropogenic climate change signal. Therefore, impact of these low-frequency variations may be particularly important when investigating the Mediterranean climate changes.

The detailed spatio-temporal features of the derived climate oscillations may serve as fingerprints for the attribution of recently observed changes, and differentiation against the radiatively forced climate change response. The oscillatory features of these components, most probably associated with the low-frequency ocean dynamics, make them also potentially useful for predictability purposes.

Overall, the results of the analysis provide robust arguments for CM2.5 to be more credible at regional and larger scales than low-resolution models like CM2.1 or the CMIP5 model suite in representing the mean and variability of the winter Mediterranean hydroclimate. These arguments give us confidence to carry out further analysis. This analysis provides a picture of anthropogenic climate change by the end of twenty-first century under conditions specified by the RCP8.5 scenario.

Large-scale changes projected with the CM2.5 model for the Mediterranean winter hydroclimate are in general agreement with those derived from CMIP3 (IPCC 2007) and CMIP5 (IPCC 2014) simulations. Our analysis shows, a distinct drying in the southern, semi-arid part of the Mediterranean and slight wetting tendencies in the northern, relatively wet part, that are consistent with the thermodynamic consequence of increasing atmospheric temperature (Held and Soden 2006; Seager et al. 2010). These changes correspond well with changes in general circulation manifested by the intensification of the meridional circulation cells, expansion of the Hadley Cell, and a northeastward shift of storm tracks (Yin 2005; Lu et al. 2007; Wu et al. 
2011), the fingerprint of global warming. It is also worth noting that the CMIP3 and CMIP5 multimodel future projections produce quite remarkable spread in simulated trend of winter Northern Annular Mode- and NAO-type meridional circulation cells. While the CMIP3 ensemble provides univocal results of strengthening of the meridional cells, the CMIP5 ensemble shows considerable intermodel differences (Cattiaux and Cassou 2013). A comparison with CM2.5 may provide important insights, having direct implications for the Mediterranean hydroclimate. We leave this issue for further investigations.

Spatial patterns and tendencies of projected Mediterranean precipitation are also largely consistent with the patterns and tendencies simulated in CMIP3 and CMIP5 projections (Giorgi and Lionello 2008). However, the spatial gradients are sharper and magnitudes are larger. Very large fractional and absolute changes in mean precipitation are found along the west coasts of the Balkan Peninsula and Turkey. Mean precipitation in these regions is projected to decrease by the end of twenty-first century up to -20 and $-25 \%$, respectively. Precipitation along some regions of Northwest Africa is projected to decrease up to $-50 \%$. The strong drying tendency in the southwestern Mediterranean is possibly related to both divergence of moisture and the intensifying temperature contrast between slowly warming SSTs along the Canary Current and rapidly warming land. This highlights the necessity for having realistically resolved climate and weather at regional scales in order to provide information relevant for communities at a local level.

Projections of daily precipitation show that extremes of the hydrological cycle will strongly intensify. However, the tendencies and spatial patterns are more distinct than the mean changes. There is a large decrease in the low percentiles (5th, 10th, 15th) of daily precipitation apparent in the whole region. Projected reductions, with maxima located in the northwest Africa coast and southeast Iberian Peninsula $(\sim 50 \%)$, the Balkan Peninsula and Turkey (30-40\%), suggest longer dry spells, consistent with Kitoh and Endo (2016).

Moreover, some regions like the Iberian Peninsula will be affected by both more frequent drought conditions and also more intense extreme rainfall. Large increases (up to $40 \%$ ) in 10-year precipitation return values will affect parts of the Italian and Balkan Peninsula, Turkey and some regions of the Iberian Peninsula. This strengthens the notion that increasing atmospheric moisture content in a future warmer world will play an important role in shaping regional extreme weather.

The intensification of heavy rainfall is not present everywhere. In the coastal regions of northwest Africa, all extreme rainfall indices analyzed in our study scale with the mean tendencies and consistently show decreases, most probably caused by a regional impact of land-sea warming contrast and air-sea interactions involving the Canary Current. This again emphasizes the complexity of Mediterranean climate and weather and hence the importance of the physical processes resolved with high-resolution modeling.

In our study we focus mainly on hydroclimatic changes projected under the RCP8.5 scenario at the end of the twenty-first century. Nevertheless, anthropogenic forcing may have an inconsequential impact much sooner. As we have shown, internal climate variations have a very important contribution, especially in the present climate. However their role is shown here to diminish within the next two-to-three decades. The evolution of spatially averaged precipitation indices over the Mediterranean sub-regions suggests that the impact of global warming will emerge from internal climate variations in the 2030-2040s.

The changes projected for the coming decades may have dramatic consequences for regional societies. More frequent extreme weather events may lead to their economic losses, but also impact their health, cultural heritage, and ecosystems. Severe drying and probability of drought conditions, impacting particularly the southern region, will negatively influence water access, industry, agriculture and ecosystem. Associated with these conditions food-, and socio-economic insecurities may trigger migration of the populations and increasing number of refugees and displaced people (EEA 2016). In contrast, precipitation extremes, intensifying especially in the northern region, may increase the probability of flooding and have a widespread impact, including regional infrastructure (e.g. transport, power and water supplies), tourism, health and security. The knowledge about the high risk related to the emerging climate phenomena may serve as an important trigger for building resilience within populations at risk, and hence support initiatives like climate change adaptation.

Acknowledgements We acknowledge a support from the Carbon Mitigation Initiative at Princeton University, sponsored by BP. The authors are grateful to Tom Delworth, Ángel Muñoz, Karin van der Wiel and Frederik Schenk for helpful comments and discussion. This work is a contribution to the Helmholtz Climate Initiative REKLIM (Regional Climate Change), a joint research project of the Helmholtz Association of German research centres (HGF).

Open Access This article is distributed under the terms of the Creative Commons Attribution 4.0 International License (http:// creativecommons.org/licenses/by/4.0/), which permits unrestricted use, distribution, and reproduction in any medium, provided you give appropriate credit to the original author(s) and the source, provide a link to the Creative Commons license, and indicate if changes were made. 


\section{References}

Alexander LV et al (2006) Global observed changes in daily climate extremes of temperature and precipitation. J Geophys Res 111:D05109

Allen MR, Robertson AW (1996) Distinguishing modulated oscillations from coloured noise in multivariate datasets. Clim Dyn 12:775-784

Allen MR, Smith LA (1996) Monte Carlo SSA: detecting irregular oscillations in the presence of colored noise. J Clim 9:33733404. doi:10.1175/1520-0442(1996)009<3373:MCSDIO>2.0 . $\mathrm{CO} ; 2$

Barkhordarian A von Storch H, Bhend J (2013) The expectation of future precipitation change over the Mediterranean region is different from what we observe. J Clim Dyn 40:225. doi:10.1007/ s00382-012-1497-7

Barnston AG, Livezey RE (1987) Classification, seasonality and persistence of low-frequency atmospheric circulation patterns. Mon Wea Rev 115:1083-1126

Battisti DS, Bhatt US, Alexander MA (1995) A modeling study of the interannual variability in the wintertime North Atlantic Ocean. J Clim 8(12):3067-3083

Bengtsson L, Hodges KI, Roeckner E (2006) Storm tracks and climate change. J Clim 19(15):3518-3543

Beniston M, Stephenson DB, Christensen OB, Ferro CAT, Frei C, Goyette S, Halsnaes K, Holt T, Jylhä K, Koffi B, Palutikof J, Schöll R, Semmler T, Woth K (2007) Future extreme events in European climate: an exploration of regional climate model projections. Clim Change 81:71-95

Byrne MP, O'Gorman PA (2015) The response of precipitation minus evapotranspiration to climate warming: why the "wet-getwetter, dry-get-drier" scaling does not hold over land. J Clim 28:8078-8092

Cattiaux J, Cassou C (2013) Opposite CMIP3/CMIP5 trends in the wintertime Northern annular mode explained by combined local sea ice and remote tropical influences. Geophys Res Lett 40:3682-3687. doi:10.1002/grl.50643

Chou C, Neelin JD, Chen C-A, Tu J-Y (2009) Evaluating the "richget-richer" mechanism in tropical precipitation change under global warming. J Clim 22:1982-2005. doi:10.1175/2008j cli2471.1

Coles S (2001) An introduction to statistical modeling of extreme values. Springer, London

Compo GP, Whitaker JS, Sardeshmukh PD, Matsui N, Allan RJ, Yin X, Gleason BE, Vose RS, Rutledge G, Bessemoulin B, Brönnimann S, Brunet M, Crouthamel RI, Grant AN, Groisman PY, Jones PD, Kruk M, Kruger AC, Marshall GJ, Maugeri M, Mok H, Nordli $\varnothing$, Ross TF, Trigo RM, Wang XL, Woodruff SD, Worley SJ (2011) The twentieth century reanalysis project. Q J R Meteorol Soc 137:1-28. doi:10.1002/qj.776

Dai A, Fung IY, DelGenio AD (1997) Surface observed global land precipitation variations during 1900-88. J Clim 10:2943-2962

Delworth TL (1996) North Atlantic interannual variability in a coupled ocean-atmosphere model. J Clim 9(10):2356-2375

Delworth TL, Broccoli AJ, Rosati A, Stouffer RJ, Balaji V, Beesley JA, Cooke WF, Dixon KW, Dunne J, Dunne KA, Durachta JW, Findell KL, Ginoux P, Gnanadesikan A, Gordon CT, Griffies SM, Gudgel R, Harrison MJ, Held IM, Hemler RS, Horowitz LW, Klein SA, Knutson TR, Kushner PJ, Langenhorst AR, Lee H-C, Lin S-J, Lu J, Malyshev SL, Milly PCD, Ramaswamy V, Russell J, Daniel Schwarzkopf M, Shevliakova E, Sirutis JJ, Spelman MJ, Stern WF, Winton M, Wittenberg WT, Wyman B, Zeng F, Zhang R (2006) GFDL's CM2 global coupled climate models. Part I: Formulation and simulation characteristics. J Clim 19(5):643-674
Delworth TL, Rosati A, Anderson W, Adcroft AJ, Balaji V, Benson R, Dixon K, Griffies SM, Lee H-C, Pacanowski RC, Vecchi GA, Wittenberg AT, Zeng F, Zhang R (2012) Simulated climate and climate change in the GFDL CM2.5 high-resolution coupled climate model. J Clim 25(8):2755-2781

Deser C, Blackmon ML (1993) Surface climate variations over the North Atlantic Ocean during winter: 1900-89. J Clim 6:1743-1753

Dunkeloh A, Jacobeit J (2003) Circulation dynamics of Mediterranean precipitation variability 1948-98. Int J Climatol 23:1843-1866

EEA report 1/2017 (2016) Climate change, impacts and vulnerability in Europe. https://www.eea.europa.eu/publications/ climate-change-impacts-and-vulnerability-2016

Emori S, Brown SJ (2005) Dynamic and thermodynamic changes in mean and extreme precipitation under changed climate. Geophys Res Lett 32(17):L17706. doi:10.1029/2005GL023272

Fasullo JT (2010) Robust land-ocean contrasts in energy and water cycle feedbacks. J Clim 23(17):4677-4693

Feser F, Barcikowska M, Krueger O, Schenk F, Weisse R, Xia L (2015) Storminess over the North Atlantic and Northwestern Europe-a review. Q J R Meteorol Soc 141:382. doi:10.1002/ qj. 2364

Gao X, Pal JS, Giorgi F (2006) Projected changes in mean and extreme precipitation over the Mediterranean region from a high resolution double nested RCM simulation. Geophys Res Lett 33:2-5

Ghil $\mathrm{M}$ et al (2002) Advanced spectral methods for climatic time series. Rev Geophys 40(1):3.4

Giorgi F (2006) Climate change hot-spots. Geophys Res Lett 33:L08707. doi:10.1029/2006GL025734

Giorgi F, Coppola E (2007) European climate-change oscillation (ECO). Geophys Res Lett 34(21):L21703. doi:10.1029/200 7GL031223

Giorgi F, Lionello P (2008) Climate change projections for the Mediterranean region. Glob Planet Chang 63(2-3):90-104

Gomes PT (2001) Relationships between Iberian rainfall variability and the North Atlantic Oscillation. In: Brunet India M, Lopez Bonilo D (eds) Detecting and modeling regional climate change. Springer, Berlin, pp 377-387

Gomes PT (2011) Interannual oscillations in winter rainfall over Europe. Iberia study case. Finisterra XLVI(91):27-45

Goubanova K, Li L (2007) Extremes in temperature and precipitation around the Mediterranean basin in an ensemble of future climate scenario simulations. Glob Planet Change 57:27-42

Haylock MR, Hofstra N, A.M.G. Klein Tank, Klok EJ, Jones PD, New M (2008) A European daily high-resolution gridded dataset of surface temperature and precipitation. J Geophys Res Atmos 113:D20119

Held IM, Soden BJ (2006) Robust responses of the hydrological cycle to global warming. J Clim 19(21):5686-5699. doi:10.1175/ JCLI3990.1

Hurrell J (1995) Decadal trends in the North Atlantic oscillation: regional temperatures and precipitation. Science 269:676-679

Hurrell JW, Van Loon H (1997) Decadal variations in climate associated with the North Atlantic oscillation. Clim Chang 36:301. doi:10.1023/A:1005314315270

Hurrell JW, Kushnir Y, Ottersen G, Visbeck M (2003) An overview of the North Atlantic oscillation. In: Hurrell JW, Kushnir Y, Ottersen G, Visbeck M (eds) The North Atlantic oscillation: climatic significance and environmental impact. American Geophysical Union, Washington, DC

Hurrell JW, Hoerling MP, Phillips AS, Xu T (2004) Twentieth century North Atlantic climate change. Part I: assessing determinism. Clim Dyn 23:371-389

IPCC (2007) Climate change 2007: the physical science basis. In: Solomon S, Qin D, Manning M, Chen Z, Marquis M, Averyt KB, 
Tignor M, Miller HL (eds) Contribution of working group I to the fourth assessment report of the intergovernmental panel on climate change. Cambridge University Press, Cambridge, UK

IPCC (2014) Climate change 2014: synthesis report. In: Pachauri RK, Meyer LA (eds) Contribution of working groups I, II and III to the fifth assessment report of the intergovernmental panel on climate change. IPCC, Geneva, Switzerland, $151 \mathrm{pp}$

Jenkinson AF (1955) The frequency distribution of the annual maximum (or minimum) values of meteorological elements. Q J R Meteorol Soc 81(348):158-171

Johanson CM, Fu Q (2009) Hadley cell widening: model simulations versus observations. J Clim 22(10):2713-2725

Joshi MM, Gregory JM, Webb MJ, Sexton DMH, Johns TC (2007) Mechanisms for the land/sea warming contrast exhibited by simulations of climate change. Clim Dyn 30:455-465

Jung $\mathrm{T}$ et al (2012) High-resolution global climate simulations with the ECMWF model in Project Athena: experimental design, model climate and seasonal forecast skill. J Clim 25:3155-3172

Kang SM, Lu J (2012) Expansion of the Hadley cell under global warming: winter versus summer. J Clim 25(24):8387-8393

Kelley C, Ting M, Seager R, Kushnir Y (2011) The relative contributions of radiative forcing and internal climate variability to the late 20th century drying the Mediterranean region. Clim Dyn. doi:10.1007/s00382-011-1221-z

Kelley C, Ting M, Seager R, Kushnir Y (2012) Mediterranean precipitation climatology, seasonal cycle, and trend as simulated by CMIP5. Geophys Res Lett. doi:10.1029/2012GL053416

Kharin VV, Zwiers FW, Zhang X, Wehner M (2013) Changes in temperature and precipitation extremes in the CMIP5 ensemble. Clim Change 119:345-357

Kitoh A, Endo H (2016) Changes in precipitation extremes projected by a $20-\mathrm{km}$ mesh global atmospheric model. Weather Clim Extremes 11:41-52 (ISSN 2212-0947)

Klein Tank AM G, Zwiers FW, Zhang X (2009) Guidelines on analysis of extremes in a changing climate in support of informed decisions for adaptation. Clim Data Monit 1500:56 (WCDMPNo 72 WMO-TD)

Koeppen W (1936) Das geographische System der Klimate. In: Koeppen W, Geiger R (eds) Handbuch der Klimatologie 3. Gebrueder Bortnaeger, Berlin

Krueger O, Schenk F, Feser F, Weisse R (2013) Inconsistencies between long-term trends in storminess derived from the 20CR reanalysis and observations. J Clim 26:868-874. doi:10.1175/ JCLI-D-12-00309.1

Kunkel KE, Karl TR, Brooks H, Kossin J, Lawrimore JH, Arndt D, Bosart L, Changnon D, Cutter SL, Doesken N, Emanuel K, Groisman PYa, Katz RW, Knutson T, O’Brien J, Paciorek CJ, Peterson TC, Redmond K, Robinson D, Trapp J, Vose R, Weaver S, Wehner M, Wolter K, Wuebbles D (2013) Monitoring and understanding trends in extreme storms: state of knowledge. Bull Am Meteorol Soc 94(4):499-514

Kushnir Y (1994) Interdecadal variations in North Atlantic Sea surface temperature and associated atmospheric conditions. J Clim 7:141-157. doi:10.1175/1520-0442(1994)007<0141:IVINAS> 2.0.CO;2

Lu J, Vecchi GA, Reichler T (2007) Expansion of the Hadley cell under global warming. Geophys Res Lett 34(6):L06805. doi:1 0.1029/2006GL028443

Manabe S, Bryan K, Spelman MJ (1990) Transient response of a global ocean-atmosphere model to a doubling of atmospheric carbon dioxide. J Phys Oceanogr 20(5):722-749

Manabe S, Stouffer RJ, Spelman MJ, Bryan K (1991) Transient responses of a coupled ocean-atmosphere model to gradual changes of atmospheric $\mathrm{CO}_{2}$. Part I: Annual mean response. $\mathrm{J}$ Clim 4(8):785-818
Mariotti A, Dell'Aquila A (2012) Decadal climate variability in the Mediterranean region: roles of large-scale forcings and regional processes. Clim Dyn 38(5):1129-1145

Meinshausen M et al (2011) The RCP greenhouse gas concentrations and their extensions from 1765 to 2300. Clim Change 109:213-241

Min SK et al (2011) Human contribution to more intense precipitation extremes. Nature 470:378-381

Moore GWK, Renfrew IA (2012) Cold European winters: interplay between the NAO and the East Atlantic mode. Atmos Sci Lett $13: 1-8$

Moore GWK, Pickart RS, Renfrew IA (2011) Complexities in the climate of the subpolar North Atlantic: a case study from the winter of 2007. Q J R Meteorol Soc 137:757-767

Moore GWK, Renfrew IA, Pickart RS (2013) Multidecadal mobility of the North Atlantic oscillation. J Clim 26(8):2453-2466

Moron VR, Vautard, Ghil M (1998) Trends, interdecadal and interannual oscillations in global sea-surface temperature. Clim Dyn 14:545-569

Murphy SJ, Washington R (2001) United Kingdom and Ireland precipitation variability and the North Atlantic sea-level pressure field. Int J Climatol 21:939-959

Nakamura H, Wallace JM (1993) Synoptic behavior of baroclinic eddies during the blocking onset. Mon Wea Rev 121(7): 1892-1903

Osborn TJ, Briffa KR, Tett SFB, Jones PD, Trigo RM (1999) Evaluation of the North Atlantic Oscillation as simulated by a coupled climate model. Clim Dyn 15(9):685-702

Paxian A, Hertig E, Seubert S, Vogt G, Jacobeit J, Paeth H (2015) Present-day and future Mediterranean precipitation extremes assessed by different statistical approaches. Clim Dyn 44:845860. doi:10.1007/s00382-014-2428-6

Plaut G, Vautard R (1994) Spells of oscillations and weather regimes in the low-frequency dynamics of the Northern Hemisphere. J Atmos Sci 51:210-236

Riahi K, Rao S, Krey V et al (2011) RCP 8.5-a scenario of comparatively high greenhouse gas emissions. Clim Change 109:33. doi:10.1007/s10584-011-0149-y

Rodo X, Baert E, Comin FA (1997) Variations in seasonal rainfall in southern Europe during the present century: relationships with the North Atlantic oscillation and the El Nino southern oscillation. Clim Dyn 13(4):275-284

Rodriguez-Puebla C, Encinas AH, Nieto S, Garmendia J (1998) Spatial and temporal patterns of annual precipitation variability over the Iberian Peninsula. Int J Climatol 18:299-316. doi:10.1002/(SICI)1097-0088(19980315)18:3<299::AIDJOC247>3.0.CO;2-L

Ruprich-Robert Y, Cassou, Clim Dyn C (2015) Combined influences of seasonal East Atlantic pattern and North Atlantic oscillation to excite Atlantic multidecadal variability in a climate model. Clim Dyn 44:229. doi:10.1007/s00382-014-2176-7

Schneider U, Becker A Finger P, Meyer-Christoffer A Rudolf B Ziese M (2011) GPCC full data reanalysis version 6.0 at $0.5^{\circ}$ : monthly land-surface precipitation from rain-gauges built on GTS-based and historic data. doi:10.5676/DWD_GPCC/FD_M_V7_050

Seager R, Kushnir Y, Visbeck M, Naik N, Miller J, Krahmann G, Cullen H (2000) Causes of Atlantic Ocean climate variability between 1958 and 1998. J Clim 13(16):2845-2862

Seager R, Naik N, Vecchi GA (2010) Thermodynamic and dynamic mechanisms for large-scale changes in the hydrological cycle in response to global warming. J Clim 23(17):4651-4668

Seager R, Liu H, Henderson N, Simpson I, Kelley C, Shaw T, Kushnir Y, Ting M (2014) Causes of increasing aridification of the Mediterranean Region in response to rising greenhouse gases. J Clim 27(12):4655-4676 
Seierstad IA, Stephenson DB, Kvamsto NG (2007) How useful are teleconnection patterns for explaining variability in extratropical storminess? Tellus A 59:170-181

Selten FM, Haarsma RJ, Opsteegh JD (1999) On the mechanism of North Atlantic decadal variability. J Clim 12:1956-1973. doi:10.1175/1520-0442(1999)012<1956:OTMONA>2.0.CO;2

Semmler T, Jacob D (2004) Modeling extreme precipitation events:a climate change simulation for Europe. Glob Planet Change 44:119-127

Sillmann J, Kharin VV Zhang X, Zwiers FW, Bronaugh D (2013) Climate extremes indices in the CMIP5 multimodel ensemble: Part 1. model evaluation in the present climate. J Geophys Res Atmos 118:1716-1733

Smith RL (2003) Statistics of extremes, with applications in environment, insurance and finance. In: Extreme values in finance, telecommunications and the environment. Chapman \& Hall, pp $1-78$

Toreti A, Naveau P, Zampieri M, Schindler A, Scoccimarro E, Xoplaki E, Dijkstra HA, Gualdi S, Luterbacher J (2013) Projections of global changes in precipitation extremes from coupled model intercomparison project phase 5 models. Geophys Res Lett 40:4887-4892

Trenberth KE (2011) Changes in precipitation with climate change. Clim Res 47:123-138

Trenberth KE et al (2007) Observations: surface and atmospheric climate change. In: Solomon S et al (eds) Climate change 2007: the physical science basis. Contribution of working group I to the fourth assessment report of the intergovernmental panel on climate change. Cambridge Univ. Press, New York, pp 235-336

Trigo RM, Osborn TJ, Corte-Real JM (2002) The North Atlantic oscillation influence on Europe: climate impacts associated physical mechanisms. Clim Res 20(1):9-17

Trigo RM, Pozo-Vazquez D, Osborn TJ, Castro-Diez Y, Gamis-Fortis S, Esteban-Parra MJ (2004) North Atlantic oscillation influence on precipitation, river flow and water resources in the Iberian Peninsula. Int J Climatol 24:925-944

van der Wiel K, Kapnick SB, Vecchi GA, Cooke W, Delworth TL, Jia L, Murakami H, Underwood S, Zeng F (2016) The resolution dependence of contiguous US precipitation extremes in response to $\mathrm{CO}_{2}$ forcing. J Clim 29:7991-8012. doi:10.1175/ JCLI-D-16-0307.1

Vicente-Serrano SM, López-Moreno JI (2008) Differences in the non-stationary influence of the North Atlantic oscillation on
European precipitation under different scenarios of greenhouse gas concentrations. Geophys Res Lett 35:L18710

von Storch H, Langenberg H, Feser F (2000) A spectral nudging technique for dynamical downscaling purposes. Mon Wea Rev 128:3664-3673

Westra S, Alexander LV, Zwiers FW (2013) Global increasing trends in annual maximum daily precipitation. J Clim 26:3904-3918

Wilks DS (2006) Methods in the atmospheric sciences, 2nd edn. Academic Press, St Louis, MO

Woollings T, Hannachi A, Hoskins B (2010) Variability of the North Atlantic eddy-driven jet stream. Q J R Meteorol Soc 136:856868. doi:10.1002/qj.625

Wu Y, Ting MF, Seager R, Huang H, Cane M (2011) Changes in storm tracks and energy transports in a warmer climate simulated by the GFDL CM2.1 model. Clim Dyn 37(1-2):53-72. doi:10.1007/s00382-010-0776-4

Xie S-P, Deser C, Vecchi GA, Ma J, Teng H, Wittenberg AT (2010) Global warming pattern formation: sea surface temperature and rainfall. J Clim 23(4):966-986

Xoplaki E (2002) Climate variability over the Mediterranean. PhD Thesis, University of Bern, Switzerland. http://sinus.unibe.ch/ klimet/docs/phd_xoplaki.pdf

Xoplaki E, Gonzalez-Rouco FJ, Luterbacher J, Wanner H (2004) Wet season Mediterranean precipitation variability: influence of large-scale dynamics. Clim Dyn 23:78. doi:10.1007/ s00382-004-0422-0

Yang S, Christensen JH (2012) Arctic sea ice reduction and European cold winters in CMIP5 climate change experiments. Geophys Res Lett 39(20):L20707. doi:10.1029/2012GL053338

Yin JH (2005) A consistent poleward shift of the storm tracks in simulations of 21 st century climate. Geophys Res Lett 32(18):L18701. doi:10.1029/2005GL023684

Zappa G, Shaffrey LC, Hodges KI (2013a) The ability of CMIP5 models to simulate North Atlantic extratropical cyclones. J Clim 26(15):5379-5396

Zappa G, Shaffrey LC, Hodges KI, Sansom PG, Stephenson DB (2013b) A multimodel assessment of future projections of North Atlantic and European extratropical cyclones in the CMIP5 climate models. J Clim 26(16):5846-5862

Zhang X et al (2007) Detection of human influence on twentieth-century precipitation trends. Nature 448:461-466 